\title{
ENERGY FLEXIBLE BUILDINGS: A METHODOLOGY FOR RATING THE FLEXIBILITY PERFORMANCE OF BUILDINGS WITH ELECTRIC HEATING AND COOLING SYSTEMS
}

\author{
Alessia Arteconi $^{1 *}$, Alice Mugnini ${ }^{1}$, Fabio Polonara ${ }^{1,2}$, \\ 1* Dipartimento di Ingegneria Industriale e Scienze Matematiche, Università Politecnica delle Marche, via brecce \\ bianche 1, 60131 Ancona, Italy \\ ${ }^{2}$ Consiglio Nazionale delle Ricerche (CNR): Construction Technologies Institute, Viale Lombardia 49, 20098
}

(San Giuliano Milanese, (MI), Italy)

Email:1a.arteconi@univpm.it,f.polonara@univpm.it,a.mugnini@pm.univpm.it

\begin{abstract}
In the present energy scenario, buildings are playing more and more as energy prosumers. They can use and produce energy and also actively manage their energy demand. The energy flexibility quantifies their potential to adjust the energy demand on the basis of external requests. The objective of this paper is to propose a method for buildings energy flexibility labelling at design conditions in the same fashion as the energy performance label. The flexibility quantification is based on the calculation of four flexibility parameters, which contribute to the definition of the Flexibility Performance Indicator. In order to assess the Flexibility Performance Indicator, buildings dynamic simulations are necessary and the boundary conditions (i.e. demand response event, representative day, comfort constraints) to be considered during the evaluation are provided as part of the proposed methodology. The method was applied to different Italian buildings, which differ for geographic location and design specifications and, in particular, the effects of building structure, heating/cooling systems and energy storage systems were compared. Results show that the climatic conditions affect the flexibility performance, while the building feature more relevant is the thermal mass of the building envelope, more than that provided by the distribution system. A sensitivity analysis to evaluate how the results are influenced by the proposed boundary conditions was also performed. Their choice confirms to have a relevant impact on flexibility quantification, then their unique definition has a paramount importance within this methodology.
\end{abstract}

Keywords: Energy Flexible Buildings, Demand Side Management, Demand Response, Flexibility Indicators, Buildings Labelling.

\section{INTRODUCTION}

Improving the energy performance of buildings is one of the main options suggested by the European Commission to reduce energy consumption and global $\mathrm{CO}_{2}$ emissions [1]. With the updated Energy Performance of Buildings Directive (EPDB) [2], the EU has defined the most important actions that Member States will have to implement in order to achieve a highly energy efficient and decarbonized building stock. The main objective is to reduce buildings energy demand by $80 \%$ compared to 1990, making all of them Nearly Zero Energy Buildings (nZEBs) by 2050 [2]. Currently, about $35 \%$ of the EU buildings are over 50 years old and almost $75 \%$ of the building stock is energy inefficient [3], therefore renovation and new buildings are necessary to comply with the new prescriptions. In addition, the transition to a nZEB stock will include a great increase of renewable energy sources (RES) as distributed generation systems [4]. In this context, buildings will become a substantial part of the energy system, acting both as producers and energy users and therefore turning into prosumers [5]. However, the generation uncertainty created by RES, together with the growing electricity demand (e.g. diffusion of electric vehicles, replacement of traditional fossil fuel boilers with heat pumps [6], growing diffusion of air conditioning technologies [7]), create the need for the implementation of the Smart Grid model [8]. An action in such direction is represented by buildings renovation aimed at reducing energy demand and increasing flexibility [9]. Indeed, in Europe, buildings are responsible for approximately $40 \%$ of energy consumption [3], therefore, the possibility to manage their energy demand can be of great help to increase the flexibility of the entire electricity system.

Heat pumps, as Annex 42 investigated [10], can be the means by which the energy storage potential of buildings is exploited. According to IEA EBC Annex 67 [9], buildings energy flexibility is defined as "the building ability to manage its demand and generation according to local climate conditions, user needs, and energy network 
requirements". Given the relevance of the share of heating and cooling energy demand, both the building structure and its HVAC (heating ventilation and air conditioning) system play an important role to achieve this flexibility without jeopardizing the occupants' comfort [11]. In the literature several solutions can be identified to manage buildings thermal demand. The thermal mass embedded in the building envelope can be used as an energy storage [12] or an external Thermal Energy Storage (TES) can be added to the HVAC system. Many studies evaluated the use of both sensible [13][14] and latent [15] TES as demand side management (DSM) instrument in buildings.

The importance of energy flexibility in buildings is highlighted by the updated EPDB [2]. Unlike the previous version [16], in which only the buildings energy labelling was required, the new one introduces the Smartness Readiness Indicator (SRI) to assess the capability of a building to adapt its operation to the needs of the occupants and of the grid [2]. The discussion on the SRI definition is open and many approaches can be distinguished to assess buildings energy flexibility. Verbeke et al. [17] define a method for the SRI calculation starting from the evaluation of each smart service integrated into the building, while the IEA EBC Annex 67 [18] idea is completely different. They propose a physical data and simulation-based approach with quantitative indicators. Actually they highlight the fact that in this way energy flexibility is not only the result of the available technologies in buildings but it depends significantly on how these technologies are used and their interaction with the surrounding energy network, the occupants and other boundary conditions, such as local climate [18]. More precisely, the methodology introduced by IEA EBC Annex 67 represents buildings energy flexibility by quantifying the amount of energy a building can shift according to an external forcing factor with the aim of minimizing energy consumption, cost, $\mathrm{CO}_{2}$ emissions of the building or a combination of those criteria [18].

There are several studies in literature that have proposed ways to quantify the energy flexibility provided buildings [19]. Reynders et al. [12] introduced a simulation-based method for the generic characterization of energy flexibility of buildings thermal mass. Through the introduction of three indicators (available structural storage capacity, storage efficiency and power shifting capability), they represent a demand response technology as a virtual storage capacity. Stinner et al. [13] also introduced a quantification method based on three different flexibility indicators: temporal flexibility (forced and delayed), power flexibility and energy flexibility. From the simulation of opposite events (charge and discharge), they evaluate the energy flexibility of buildings heating systems with a thermal storage tank used both for space heating and for domestic hot water. Le Dréau and Heiselberg [20] evaluated discharged heat, charged heat and shifting efficiency of heat storage systems. De Coninck and Helsen [21] developed a methodology to quantify energy flexibility provided by thermostatically controlled loads (TCL) based on the introduction of cost functions, which represent how much shifting energy use at a specific time costs. D'hulst et al. [22] defined a flexibility quantification method depending on the estimation of the power consumption increase and decrease that can be realized at a certain time of the day, combined with how long this power increase or decrease can be sustained. They applied this method to different types of domestic appliances, like washing machines, domestic refrigerators, tumble dryers, dishwashers, domestic hot water buffers and electric vehicles, to evaluate the whole energy flexibility potential of a building. Nuytten et al. [23] quantified the energy flexibility of Combined Heat and Power (CHP) system with thermal energy storage by means of the number of hours the energy use can be delayed or anticipated.

Regardless the method used, it is important to underline that buildings energy flexibility can be evaluated at two different levels: the operational level and the design level [24]. The first one is the approach proposed by IEA EBC Annex 67 with the method suggested by Junker et al. [25]. In their work the energy operational flexibility characterization is made by means of a dynamic function which describes the reaction of a specific smart building, or cluster of smart buildings, to a penalty signal derived from specific grid requests. The second approach, analysed in 
the present work, aims at the characterization of energy flexibility on the basis only of buildings design specifications, in a similar fashion as for energy labelling assessment. The design approach is relevant for rating buildings on the basis of potential available flexibility and can help in the design stage to achieve minimum flexibility requirements when new buildings are built or old ones are renovated.

The objective of this work is to propose a methodology for buildings flexibility labelling, which can be an important information to be included also in the energy performance certificate (EPC) [2]. The definition of a new single indicator, the Flexible Performance Indicator (FPI), is introduced with the proposed methodology and it allows the identification of the building flexibility class. The FPI depends on the most relevant parameters for energy flexibility, those suggested in the available studies in literature [12], with a focus on electric demand, because the flexibility provided to the electricity grid is considered. Indeed, the main novelty of this work is the introduction of the FPI, which, with a single value, can summarize and weight all the different aspects affecting the energy flexible behaviour of a building, which are mainly related to the thermal inertia of the building, the thermal inertia of the distribution system and the performance of the heating/cooling system. Furthermore, given the relevance of the boundary conditions on the available energy flexibility [26], reference conditions to be assumed during the calculation procedure are proposed. In the paper the method is tested (through dynamic simulation) with different building construction features or HVAC systems in order to evaluate its reliability and robustness.

The work is divided into four parts. Section 2 presents the approach used in the analysis and the standard boundary conditions definition. In Section 3 the flexibility quantification methodology and the FPI formulation are described, while in Section 4 the application of the FPI to different cases is presented. Results are discussed in Section 5, where also a sensitivity analysis by varying the boundary conditions is provided. Eventually main conclusions are summarized in Section 6.

\section{METHODS AND BOUNDARY CONDITIONS}

The objective of this paper is introducing a methodology for buildings energy flexibility labelling. The method is based on a standard procedure that allows the assessment of the electric flexibility performance of buildings equipped with electrically driven heating and cooling systems, e.g. heat pumps. Unlike the buildings energy efficiency assessment (EPC), based on a steady state approach, the energy flexibility evaluation requires a dynamic analysis. Indeed, when the building energy flexibility is activated, it means that the building is pushed to deviate its demand towards a new profile generally aimed at compensating power imbalances in the grid [24]. Since the buildings energy demand depends on the dynamic of the system itself and on external environment (i.e. ambient temperature, solar gains, etc.), the building response cannot be evaluated considering fixed boundary conditions. For these reasons the method is simulation-based and requires a transient simulation tool. Besides, as Reynders et al. [12] highlighted, the result of a demand side management event is not univocal but it is affected by the imposed boundary conditions. Therefore, the first purpose of this study is to identify suitable boundary conditions that can be easily replicated and identified in an unambiguous manner when the FPI is calculated. The FPI is defined in order to include in its definition the most relevant variables for a flexible behaviour [27]. Eventually the method is tested with some case studies, where geographical position and thermal inertia, introduced by both buildings envelope (construction materials or wall composition) and HVAC systems, assume different values. In this way the aspects with a bigger impact on buildings flexibility behaviour are highlighted and the ability of the FPI to take them into account is discussed. 


\subsection{Boundary Conditions}

The boundary conditions which affect the energy flexibility assessment are: (i) the demand response event; (ii) the thermal comfort constraints; (iii) the weather data and DR event reference day. The following sub-sections describe them in detail.

\subsubsection{Demand Response}

Demand Response (DR) is a particular DSM program, defined as 'changes in electric usage implemented directly or indirectly by end-use customers/prosumers from their current/normal consumption/injection patterns in response to certain signals', typically price signals [24]. A DR strategy can be designed for different purposes, such as peak shaving, valley filling, energy conservation, etc [14]. Due to its importance on improving the electricity grid reliability [28] and on reducing the generation capacity, a peak shaving strategy (PSS) was chosen for the proposed method (Figure 1). During the PSS the thermostatically controlled loads are managed to reduce the demand during peak periods [24] by means of a rule-based control (RBC), which varies the comfort temperature set-points [29].

The PSS consists in interrupting power supply to the heating/cooling system at the electric grid peak power demand time, i.e. during the High Load Period (HLP), until the internal comfort conditions reach a desired lower bound. This is the first phase of the DR event, called "response period". Then the heating/cooling system is switched on to restore the initial internal comfort conditions. This is the second DR phase: the "recovery period".

\subsubsection{Thermal comfort constraints}

Regarding the comfort bounds, in accordance with Fanger's Thermal Comfort [30], acceptable bands are defined. For the heating season the comfort temperature ranges between $20^{\circ} \mathrm{C}-22^{\circ} \mathrm{C}$. For the cooling season the comfort temperature ranges between $24^{\circ} \mathrm{C}-26^{\circ} \mathrm{C}$ with $60 \% \pm 10 \%$ for the indoor relative humidity (RH). Therefore, during the DR event, for the heating case a $2^{\circ} \mathrm{C}$ decrease is allowed starting from a set-point temperature of $22^{\circ} \mathrm{C}$, while for the cooling case the temperature can increase $2^{\circ} \mathrm{C}$ from a temperature set-point of $24^{\circ} \mathrm{C}$ and, if it can be controlled, a $10 \%$ RH increase is allowed.

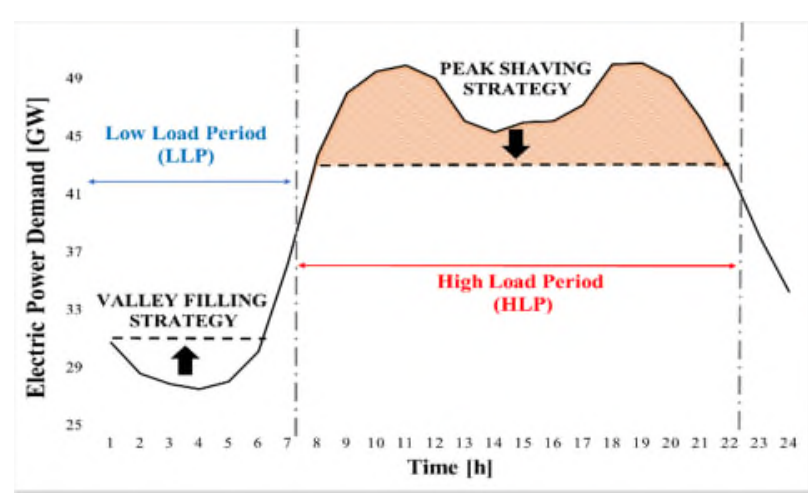

Figure 1. Two types of DR events, a Peak Shaving Strategy (PSS) during High Load Period (HLP) and a Valley Filling Strategy (VFS) during Low Load Period (LLP).

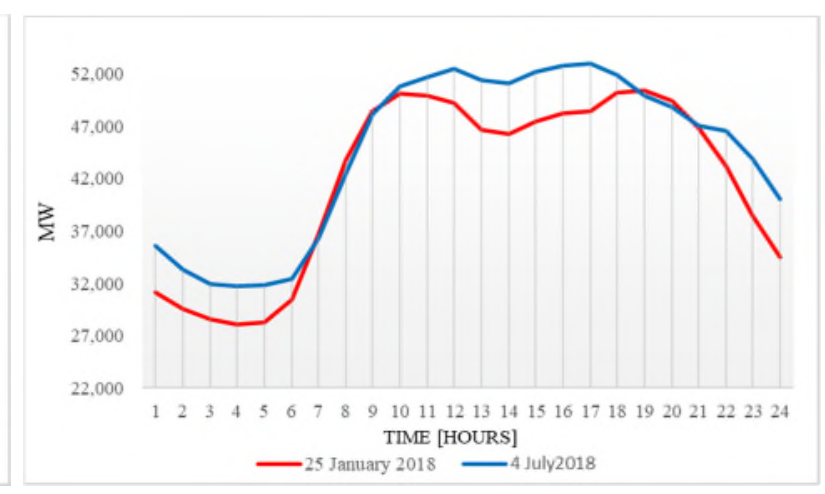

Figure 2. Two Italian daily electric power demand curves, 25 January 2018 and 4 July 2018.

\subsubsection{Weather data and DR event reference day}

As far as the external environment is concerned, a climatic file must be used to model the dynamic behaviour of the building under variable ambient conditions: a typical meteorological year (TMY) must be considered for each location [31] where, among the others, the outside ambient air temperature, the solar radiation and the wind speed are available. 
Regarding the DR event representative day, a reference day and starting time must be selected. First of all, the most representative day of summer and winter season must be identified. It is recommended to refer to available standard data. For example in Italy the reference standard is UNI 10349-1 [32], where the climatic data to assess the buildings energy performance are reported. Here it is possible to identify the average daily temperatures for each month and for the most representative Italian cities with a weather station. Given the location, the lowest average daily temperature indicated by the standard in winter and the highest average daily temperature in summer are taken, in order to capture the most extreme cases. This method proposes to select as representative day from the climatic file that one whose average daily temperature matches better ${ }^{1}$ with the values obtained from the standard. Attention must also be paid to the daily temperature excursion, because if more days could satisfy the proposed criterion, the one which better represents the daily temperature variation in the location should be considered.

Once the day is identified, it is also necessary to set the starting time of the DR event. Since the DR strategy chosen is a PSS, it is suggested to evaluate the peak electricity demand times for the country where the building is located. And if, as for the Italian case, there are more peak times, the worst scenario for the specific season must be chosen. For example, from the daily balancing data available on Terna website [33], the Italian electricity demand has always two peaks, one in the first part of the day and the other in the second part (Figure 2). In winter the first peak occurs between $10.00 \mathrm{am}$ and $12.00 \mathrm{pm}$, and the second one between $6.00 \mathrm{p} . \mathrm{m}$. and $7.00 \mathrm{pm}$. In summer, instead, the first peak occurs between $12.00 \mathrm{pm}$ and $1.00 \mathrm{pm}$ and the second one between 5.00 and $6.00 \mathrm{pm}$. Thus, considering the most severe cases, the Italian DR starting time to be used in the proposed methodology is $7.00 \mathrm{pm}$ for the heating case and $12.00 \mathrm{pm}$ for the cooling case.

Figure 3 illustrates as example the indoor temperature trend given the boundary conditions specified above for the Italian context.

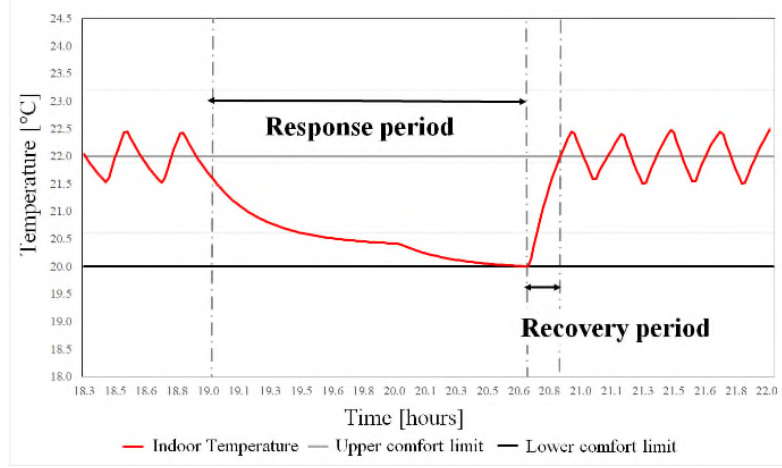

Figure 3. Indoor temperature during the DR event in heating case. The duration of response and recovery period is shown.

\section{ENERGY FLEXIBILITY QUANTIFICATION AND LABELLING METHOD}

In this section the methodology to quantify and label the buildings energy flexibility is described. As Reynders et al. [12] highlighted through an extensive literature review, three variables are fundamental to have an energy flexibility quantification: time, (i.e. duration), capacity (amount of energy that can be shifted per time unit) and cost (potential cost saving). The quantification method proposed in this work aims at calculating a single indicator (the Flexibility Performance Indicator, FPI) which includes all the abovementioned buildings energy flexibility typical aspects. In particular, the proposed FPI depends on four flexibility parameters. The first parameter is the response time tres [hours]. It represents the time necessary to the internal temperature to reach the lower or upper comfort temperature

\footnotetext{
${ }^{1}$ Rounding up or down in cooling and heating cases respectively.
} 
bound respectively in winter and summer. This parameter quantifies how much time the heating/cooling generator can remain off while the building can maintain comfort conditions. The second one is the committed power $\dot{\mathbf{P}}_{\text {res }}$ $\left[\mathrm{kW}_{\mathrm{e}}\right]$. It represents the effect of the DR event in terms of electrical power engaged. It is defined as the integral of the difference between the heat pump reference power demand (i.e. without DR) and the HP power demand during the DR event divided by the duration of the response phase, i.e. tres (eq. 1). $\dot{\mathbf{P}}_{\mathbf{R E F}}$ refers to normal operation of the system, when no DR event is in place, and it represents the HP electric power demand for heating/cooling during the same period in the representative day as for the DR event.

$\dot{P}_{\text {res }}=\frac{1}{t_{\text {res }}} \int_{0}^{t_{r e s}}\left(\dot{P}_{R E F}-\dot{P}_{D R}\right) d t$

These two parameters are more interesting for the electric grid side. Indeed, they refer to the response period when the heating/cooling systems are switched off and then the network load is reduced. The next two parameters, on the other hand, are of greater interest for the user side, because they consider how fast the initial comfort is restored after a DR event and the actual DR impact on energy use. The third parameter is the recovery time trec [hours], i.e. the duration of the recovery period, and the fourth is the actual energy variation $\mathbf{E}_{\mathbf{D R}}\left[\mathrm{kWh} \mathrm{h}_{\mathrm{e}}\right]$. The latter is defined as the difference in energy use between the reference condition and the DR event during the whole DR event, i.e. $t_{D R}$ (eq. 2).

$E_{D R}=\int_{0}^{t_{D R}}\left(\dot{P}_{R E F}-\dot{P}_{D R}\right) d t$, with $t_{D R}=t_{r e s}+t_{r e c}$

Thus the flexibility performance indicator is defined in a dimensionless form as weighted average of four contributions, as shown in Eq. 3:

$F P I=\frac{1}{4}\left(p_{1} \cdot t_{r e s}^{*}+p_{2} \cdot \dot{P}_{r e s}^{*}-p_{3} \cdot t_{r e c}^{*}+p_{4} \cdot \eta_{D R}\right)$

With:

$$
\begin{aligned}
& t_{r e s}^{*}=\frac{t_{r e s}}{24} \\
& \dot{P}_{\text {res }}^{*}=\frac{\left|\dot{P}_{\text {res }}\right|}{\dot{P}_{\text {rated }}} \text {, with } \dot{P}_{\text {rated }} \text { is the HP design power } \\
& t_{\text {rec }}^{*}=\frac{t_{r e c}}{24} \\
& \eta_{D R}=\left\{\begin{array}{c}
\frac{E_{D R}}{\int_{0}^{t} D R\left(\dot{P}_{R E F}\right) d t} \\
0 \text { if } E_{D R}<0 \text { in PSS }
\end{array}\right.
\end{aligned}
$$

The first term in the FPI definition is the response time, $t_{\text {res }}$, referred to 24 hours, with a weight of $60 \%\left(p_{1}=60\right)$. The second is $\dot{\mathrm{P}}_{\text {res }}$ normalized to the installed rated power $\left(\dot{\mathrm{P}}_{\text {rated }}\right)$ with a weight of $20 \%\left(\mathrm{p}_{2}=20\right)$. The third is $\mathrm{t}_{\text {rec }}$ normalized on 24 hours with a weight of $10 \%\left(\mathrm{p}_{3}=10\right)$ and the last one is a sort of DR energy efficiency, since it is calculated as the ratio between the actual energy variation achieved during the $\mathrm{DR}$ event $\left(\mathrm{E}_{\mathrm{DR}}\right)$ and the building electricity use in reference operation (without DR event) during tDR. It has a weight of $10 \%\left(\mathrm{p}_{4}=10\right)$. As highlighted in Eq. 7, the DR energy efficiency is zero if the PSS does not produce any energy saving.

The weights distribution was determined with an empirical approach by observing simulation data representing the behaviour of a large amount of buildings configurations during a DR event. They are assigned to emphasize the impact 
of the DR event on the electricity grid. Thus a greater weight is given to those parameters which represent the interaction with the grid side (i.e. $\mathrm{p}_{1}$ and $\mathrm{p}_{2}$ ).

\subsection{Flexibility class}

In order to rate a building in a specific flexibility class, the same approach as the energy labelling was used. An ideal reference condition was assumed to calibrate the actual building flexibility and reduce the influence of the building location (i.e. weather data), thus to compare fairly the performance of buildings in different climatic zones. In the ideal reference condition a building with the same thermal resistance of the building under evaluation is taken, but its thermal mass (both for the envelope and heating/cooling distribution system) is neglected. It is assumed that the building is subject to the same DR event when the outside ambient temperature is constant at the design value used to size the heating and cooling systems, respectively in winter and summer (see Section 4.2). An FPI limit value in steady state conditions is calculated (see assumptions in Table 1) and it refers to an extreme case where the inertia of the building is neglected and the heating/cooling system load is always at its design value. The reference condition represents a configuration with limited flexibility due to thermal mass but with a fast responsiveness of the heating/cooling system (it works always at nominal conditions), then it is assumed to be a medium flexibility level and it is set in class B. The flexibility class for the considered building is determined on the basis of the ratio between FPI and FPI limit, as represented in Figure 4, where the subdivision in classes was set variations of such ratio based on 0.3 multiples.

Table 1. Description of method and assumptions for $\mathrm{FPI}_{\text {limit }}$ calculation.

\begin{tabular}{|c|c|c|}
\hline Variable & Method of calculation & Assumptions \\
\hline $\mathrm{t}_{\text {res }}$ & $\begin{array}{l}\text { Calculated as the energy necessary to } \\
\text { produce a } 2^{\circ} \mathrm{C} \text { variation of the indoor air } \\
\text { divided by the net value of thermal losses } \\
\text { and gains }\end{array}$ & $\begin{array}{l}\text { - Thermal losses are assessed considering an average } \\
\text { indoor condition } 21^{\circ} \mathrm{C} \text { in winter and } 25^{\circ} \mathrm{C} \text { and } 60 \% \text { UR in } \\
\text { summer }[34,35] \\
\text { - Solar gains and internal gains are considered only in } \\
\text { summer } \\
\text { - In summer the internal gains include both sensible and } \\
\text { latent contributions if the plant can control the HR }\end{array}$ \\
\hline $\mathrm{t}_{\mathrm{rec}}$ & $\begin{array}{l}\text { Calculated as the energy necessary to } \\
\text { produce a } 2^{\circ} \mathrm{C} \text { variation of the indoor air } \\
\text { divided by the heating/cooling system } \\
\text { nominal capacity }\end{array}$ & \\
\hline Pres & Equal to nominal power & $\begin{array}{l}\text { - The heating/cooling system without DR event works at } \\
\text { fixed conditions equal to design values }\end{array}$ \\
\hline $\mathrm{E}_{\mathrm{DR}}$ & Calculated as in eq. 2 & $\begin{array}{l}\text { - In case without DR event the heating/cooling system } \\
\text { works for the whole period at nominal power } \\
\text { - In case with DR event the heating/cooling system works } \\
\text { during trec at nominal power }\end{array}$ \\
\hline
\end{tabular}

\begin{tabular}{|c|c|c|}
\hline & Class A3 & $\geq 3.6 \mathrm{FPI}_{\text {limit }}$ \\
\hline $2.4 \mathrm{FPI}_{\text {limit }} \leq$ & Class A2 & $<3.6 \mathrm{FPI}_{\text {limit }}$ \\
\hline $1.5 \mathrm{FPI}_{\text {limit }} \leq$ & Class A1 & $<2.4 \mathrm{FPI}_{\text {limit }}$ \\
\hline $\mathrm{0.9} \mathrm{FPI}_{\text {limit }} \leq$ & Class B & $<1.5 \mathrm{FPI}_{\text {limit }}$ \\
\hline $\mathbf{0 . 6}^{\mathrm{FPI}}$ llimit $_{\text {lim }} \leq$ & Class C & $<0.9 \mathrm{FPI}_{\text {limit }}$ \\
\hline & Class D & $<0.6 \mathrm{FPI}_{\text {limit }}$ \\
\hline
\end{tabular}

Figure 4. Energy flexibility classes for buildings labelling.

On the basis of the results obtained and illustrated in detail in the following sections, it was possible to make some generalizations and find average values of the parameters composing the FPI. In particular it was observed that for the 
different analysed configurations the "recovery time", the "dimensionless committed power" and the "DR event energy efficiency" assume the average values reported in Table 2. Given the above mentioned parameters, the response time varies as specified in Table 2 for every defined class and it gives an idea of the time the considered building can be independent from the grid.

Table 2. Minimum response time to label buildings in a specific flexibility class given the average values of recovery time, dimensionless committed power and DR event energy efficiency for different analysed configurations (in Turin).

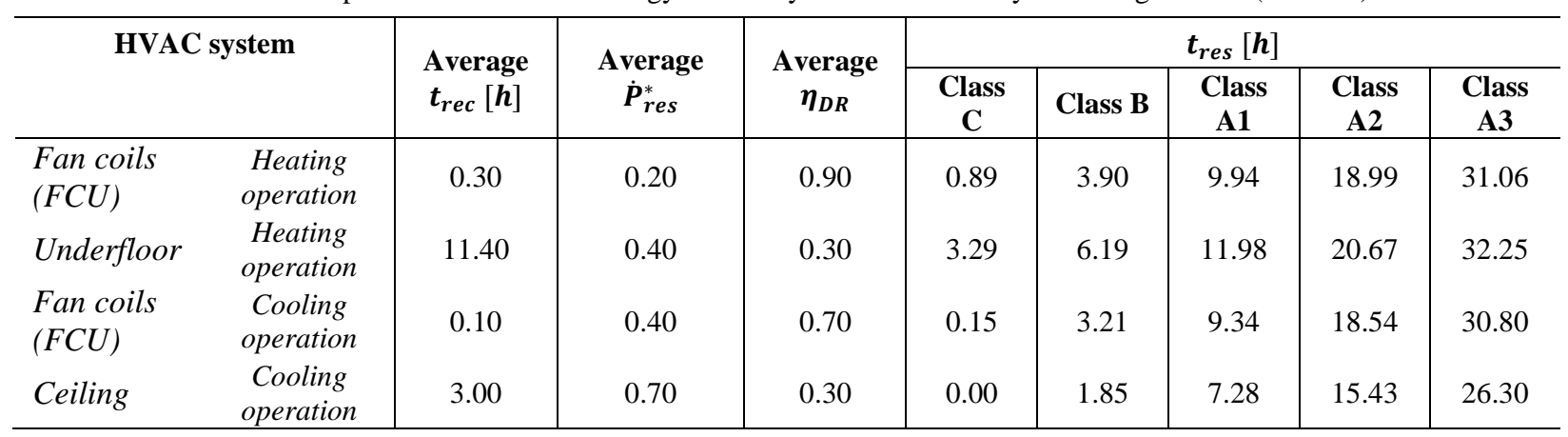

In Figure 5 the steps to implement the flexibility labelling methodology are summarized.

\begin{tabular}{|c|c|c|}
\hline STEP 1 & Select the building type of interest & $\begin{array}{l}\text { Develop a model in dynamic energy } \\
\text { simulation environment }\end{array}$ \\
\hline STEP 2 & Choose the location & Select a TMY as climatic file \\
\hline STEP 3 & DR event & PSS realized by TCL \\
\hline & & Most representative days of summer and \\
\hline STEP 4 & Choose the DR event day & winter season according to a National \\
\hline \multirow{2}{*}{ STEP 5} & Choose the DR event time & \multirow{2}{*}{$\begin{array}{l}\text { Time when the peak of the demand most } \\
\text { often occurs }\end{array}$} \\
\hline & & \\
\hline STEP 6 & $\begin{array}{l}\text { Setting comfort conditions for reference } \\
\text { simulation and run REF case }\end{array}$ & $\begin{array}{l}\cdot 24^{\circ} \mathrm{C} \text { and } 60 \% \mathrm{HR} \text { in cooling case } \\
\cdot 22^{\circ} \mathrm{C} \text { in heating case }\end{array}$ \\
\hline STEP 7 & $\begin{array}{l}\text { Setting comfort conditions for DR event } \\
\text { simulation and run DR case }\end{array}$ & $\begin{array}{l}\cdot 24-26^{\circ} \mathrm{C} \text { and } 50-70 \% \mathrm{HR} \text { in cooling case } \\
\cdot 20-22^{\circ} \mathrm{C} \text { in heating case }\end{array}$ \\
\hline STEP 8 & $\begin{array}{c}\text { Flexibility parameters and FPI } \\
\text { calculation }\end{array}$ & Calculate eq 3 , using results of step 6 and 7 \\
\hline & \multirow{2}{*}{$\begin{array}{c}\text { Calculate eq } 3 \text { with assumption reported in } \\
\text { Table } 1\end{array}$} \\
\hline STEP 9 & FPI $_{\text {limit }}$ calculation & \\
\hline & & \multirow{2}{*}{$\begin{array}{c}\text { Calculate the ratio } \frac{\mathrm{FPI}}{\mathrm{FPI}_{\mathrm{Iimit}}} \text { and use Fig. } 4 \text { to } \\
\text { identify the flexibility class }\end{array}$} \\
\hline STEP 10 & Flexibility class evaluation & \\
\hline
\end{tabular}

Figure 5. Steps to implement the flexibility labelling methodology.

\section{FPI APPLICATION: CASE STUDIES}

In this section the FPI is calculated for different buildings in order to evaluate the reliability of the methodology. As highlighted also by Foteinaki et al. [26], the available energy flexibility is affected by several variables, such as the weather data, the building envelope characteristics, etc. With more detail, in the considered case studies the following aspects where taken into account: 
- Weather: different climatic zones are assumed as building location.

- Building specifications: variation of the wall stratigraphy, overall thermal transmittance and light- or heavyweight construction are tested.

- HVAC system: air water heat pumps (AWHP) coupled with radiant distribution systems or fan coils units (FCU), with or without thermal energy storage are considered.

In the analysis, the Italian scenario was assumed, but the methodology can be applied in any country. The same consideration can be extended to the case studies considered. They try to represent a large share of building configurations in order to analyse the FPI variation, however, the proposed indicator can be calculated for every building. The description of the modelled buildings is provided in Section 4.1, while in Section 4.2 the HVAC systems features and sizing are explained. TRNSYS was used as dynamic simulation tool [36]. Weather data were obtained through Meteonorm V 5.0.13 [37].

\subsection{Buildings features}

As starting reference for the construction characteristics of the considered buildings, the Italian regulation D.M. 11 March 2008 [38] was assumed, because it is representative of a consistent share of the building stock where the heat pump technology can be integrated. The prescribed thermal transmittances (U-value) of the building envelope for two different climatic zones are reported in Table 3. In particular here the two extreme climatic zones in Italy were selected (i.e. B and E). Messina ( $\left.38^{\circ} 11^{\prime} \mathrm{N}, 15^{\circ} 32^{\prime} \mathrm{E}\right)$ was considered as reference city for the climate zone B (707 DD, degree days) and Turin $\left(45^{\circ} 7^{\prime} \mathrm{N}, 7^{\circ} 43^{\prime} \mathrm{E}\right)$ for the climatic zone E (2617 DD).

Table 3. Climatic zones characteristics, related design temperatures for heating and cooling systems and thermal transmittance of the building envelope [38]

\begin{tabular}{c|c|c|c|c|c|c|c|c|c}
\hline $\begin{array}{c}\text { Climatic } \\
\text { zone }\end{array}$ & DD & $\begin{array}{c}\text { Average } \\
\text { winter } \\
\mathbf{T}\left[{ }^{\circ} \mathbf{C}\right]\end{array}$ & $\begin{array}{c}\text { Average } \\
\text { summer } \\
\mathbf{T}\left[{ }^{\circ} \mathbf{C}\right]\end{array}$ & $\begin{array}{c}\text { Design } \\
\text { summer } \\
\mathbf{T}\left[{ }^{\circ} \mathbf{C}\right]\end{array}$ & $\begin{array}{c}\text { Design } \\
\text { winter } \\
\mathbf{T}\left[{ }^{\circ} \mathbf{C}\right]\end{array}$ & $\begin{array}{c}\mathbf{U} \text { _external walls } \\
{\left[\mathbf{W m}^{-2} \mathbf{K}^{-1}\right]}\end{array}$ & $\begin{array}{c}\mathbf{U} \text { _roof } \\
{\left[\mathbf{W m}^{-2} \mathbf{K}^{-1}\right]}\end{array}$ & $\begin{array}{c}\mathbf{U} \mathbf{f l o o r s} \\
{\left[\mathbf{W m}^{-2} \mathbf{K}^{-1}\right]}\end{array}$ & $\begin{array}{c}\mathbf{U} \_\mathbf{w i n d o w s} \\
{\left[\mathbf{W m}^{-2} \mathbf{K}^{-1}\right]}\end{array}$ \\
\hline B & 707 & 11.8 & 25.9 & 32.3 & 5 & 0.48 & 0.38 & 0.49 & 3.0 \\
E & 2617 & 5.8 & 23.2 & 31.0 & -8 & 0.34 & 0.30 & 0.33 & 2.2 \\
\hline
\end{tabular}

In order to evaluate the effect of the envelope thermal inertia on the buildings energy flexibility, the building walls were modelled with different compositions and thermal properties of the construction materials. Furthermore the wall stratigraphy was varied by changing the position of the thermal insulation and three different insulation techniques were used for the envelope so to model both refurbished buildings and new constructions [39]. They are external, internal and cavity wall insulation (insulation thermal conductivity $0.04 \mathrm{~W} / \mathrm{mK}$ ). For each insulation position, two different weights for the walls, which differ in the heaviness of the load-bearing layers, were distinguished. They are: solid bricks (density $1800 \mathrm{~kg} / \mathrm{m}^{3}$, thermal conductivity $0.72 \mathrm{~W} / \mathrm{mK}$ and specific heat $1000 \mathrm{~J} / \mathrm{kg} \mathrm{K}$ ) and hollow bricks (density $1000 \mathrm{~kg} / \mathrm{m}^{3}$, thermal conductivity $0.34 \mathrm{~W} / \mathrm{mK}$ and specific heat $1000 \mathrm{~J} / \mathrm{kg} \mathrm{K}$ ) [40], afterwards they are indicated respectively as light $(\mathrm{L})$ and heavy $(\mathrm{H})$ structure. The wall composition and thermal properties of the construction materials were extrapolated from the Italian building norms: UNI/TR 11552 [40], UNI 10351 [41] and UNI EN12524 [42]. Figure 6 shows all the modelled walls stratigraphy. Even the effect of the overall thermal transmission variation was taken into account, decreasing its value down to the latest limits prescribed by law (external walls $\mathrm{U}$ value in Turin equal to $0.28 \mathrm{~W} / \mathrm{m}^{2} \mathrm{~K}$ ) [43]. 


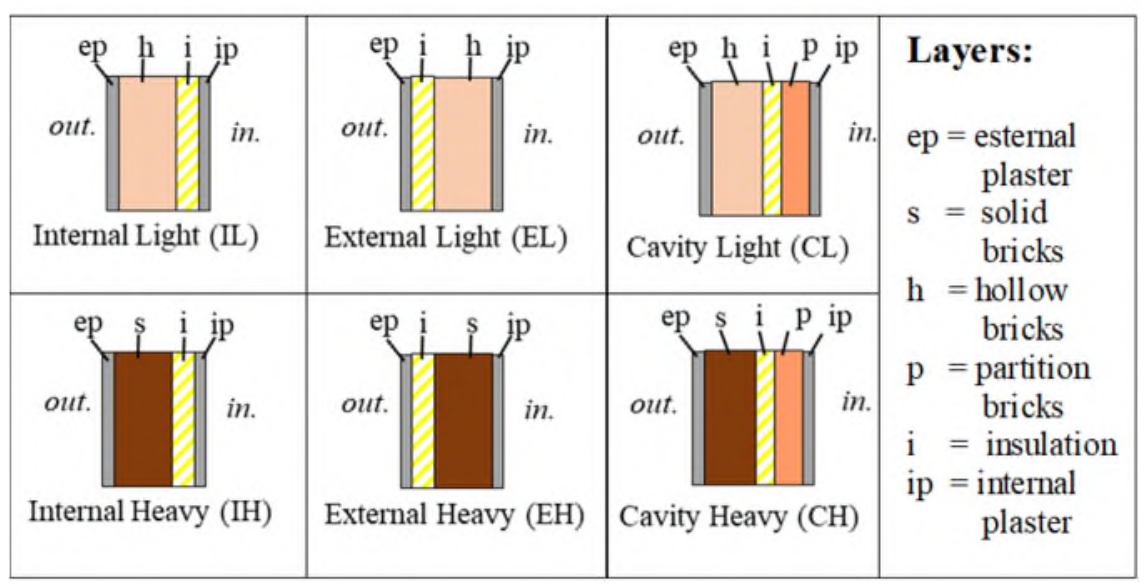

Figure 6. External walls stratigraphy: the use of light weight (L) or heavy weight $(\mathrm{H})$ materials and the position of the insulation (internal, I; external, E; central, C) are highlighted.

The selected building typology is the apartment, since this type of dwelling is the most widespread in Italy [44]. All the dwellings were considered on a raised floor, with a wall and the floor adjacent to another apartment. In all cases, the dwellings are on the top floor of the building and have an area of $100 \mathrm{~m}^{2}(10 \mathrm{~m} \times 10 \mathrm{~m} \times 3 \mathrm{~m})$. For each external wall, $15 \%$ of window surface area rate was assumed [45]. The air changes per hour (ACH) are equal to $0.5 \mathrm{~h}^{-1}$. An occupancy density of $30 \mathrm{~m}^{2}$ per person with a corresponding internal gain of $120 \mathrm{Watt} /$ person [46] and an artificial light density ${ }^{2}$ of $10 \mathrm{~W} / \mathrm{m}^{2}[34]$ were considered.

\subsection{HVAC systems}

Being the energy flexibility provided to the electricity grid the focus of the analysis, heat pumps are considered as generation system for building heating and cooling. Indeed, as Fisher and Madani highlight [47], heat pumps allow an active demand side management to support the realization of the smart grid, since from their coupling with thermal storages, the electricity consumption can be decoupled from heating/cooling demand.

In this work, all the buildings were equipped with an ON-OFF air to water reversible heat pump (AWHP), whose performance was derived from a manufacturer catalogue [48]. Two different heating and cooling distribution systems were modelled: a high/medium thermal inertia radiant system (i.e. underfloor heating system and chilled ceiling) and a low thermal inertia emission system (i.e. Fan Coils Units, FCU). These two plants were chosen because considered the best available technologies, respectively for new buildings or mild renovations, to be coupled with heat pumps.

The heating systems were sized on the basis of the maximum thermal load of the buildings in stationary conditions, considering the outdoor temperature equal to the minimum winter temperature for the chosen locations, as suggested by UNI ENI 10349-2 [35]. While the cooling systems were sized by means of the Carrier-Pizzetti technical dynamic method [49] [50]. This method makes it possible to estimate the summer thermal load (sensible and latent contribution) at different hours of the day, having as inputs the geographical coordinates, the structure characteristics (mass and thermal transmittance) and the maximum external temperature: the maximum value is assumed as peak cooling demand. In Messina, the heating load was calculated to be $2.8 \mathrm{~kW}$ at design conditions represented by an outside temperature of $+5^{\circ} \mathrm{C}$ and a room temperature of $21^{\circ} \mathrm{C}$, while in Turin it was assessed at $4.1 \mathrm{~kW}$ with a design outside temperature of $-8^{\circ} \mathrm{C}$ and the same internal temperature set-point. As regards the cooling peak load, in Messina the

\footnotetext{
${ }^{2}$ Artificial light turns on if total horizontal radiation (THR) is less than $120 \mathrm{~W} / \mathrm{m}^{2}$ and it turns off if THR is bigger than $200 \mathrm{~W} / \mathrm{m}^{2}$
} 
outside design temperature of $32.3^{\circ} \mathrm{C}$ with a daily temperature variation of $6^{\circ} \mathrm{C}$ and an internal temperature of $25^{\circ} \mathrm{C}$ with $60 \% \mathrm{HR}$ were used in the assessment. Sensible thermal loads of $4.8 \mathrm{~kW}$ and $5 \mathrm{~kW}$ were estimated for the building heavy and light structures, respectively. The latent contribution is about $1.2 \mathrm{~kW}$ for both cases. For Turin, the design cooling load was evaluated as 4.3 and $4.5 \mathrm{~kW}$ for the building heavy and light structures, respectively, with an outside temperature of $31^{\circ} \mathrm{C}$ and a daily temperature variation of $11^{\circ} \mathrm{C}$ (the internal conditions are the same as in Messina). The latent contribution is about $1 \mathrm{~kW}$ for both cases.

\subsubsection{High/medium thermal inertia HVAC system}

It is composed of an AWHP coupled with a radiant distribution system, underfloor for the heating case and chilled ceiling for the cooling case. The cooling system includes also a dehumidifier to control the internal humidity. For the purposes of this analysis the heating and cooling periods were evaluated separately, thus the HVAC systems were designed for each specific case.

In the heating season the heat pump (Type941) was sized to cover $70 \%$ of the building peak demand, as typically assumed in presence of high thermal inertia distribution systems [14]. The pipes of the underfloor heating system are embedded in a screed layer $(0.08 \mathrm{~m})$ with a wheelbase of $0.2 \mathrm{~m}$. The hot water is supplied in the temperature range $30-45^{\circ} \mathrm{C}$, with an inlet and outlet design temperature differences of $5^{\circ} \mathrm{C}$ [51]. The radiant floor was modelled through the "active layer" in TRNBild [52]. In this case, the system was not equipped with a storage tank, since the thermal inertia introduced by the floor is sufficient to limit the on-off cycles of the heat pump [14].

In cooling mode, the HP was sized to cover only the amount of sensible heat. The treatment of latent heat was entrusted to an internal air dehumidifier (modelled with Type 688). In this case, both the internal temperature and relative humidity can be controlled. To avoid superficial condensation, the cold water was supplied to the ceiling at a temperature of about $16-18^{\circ} \mathrm{C}$, with a design temperature difference of $5^{\circ} \mathrm{C}$. The chilled ceiling is composed of pipes set on panels in the first internal layer of the roof, for this reason it is considered a medium thermal inertia system if compared with underfloor systems.

\subsubsection{Low thermal inertia HVAC system}

It is composed of an AWHP coupled with FCU, used both for heating and cooling season. In this case the heat pump was sized to cover the whole heating thermal load and a small water tank was introduced to limit the on-off cycles of the heat pump (40 and 60 litres for models placed respectively in Messina and in Turin). The water supply to the heating system is regulated by means of a compensation curve depending on the outside air temperature and the design temperature difference between inlet and outlet water is about $10^{\circ} \mathrm{C}$, being the AWHP outlet water temperature in the range of $45-55^{\circ} \mathrm{C}$. The air flowrate was calculated ensuring an air temperature of at least $35^{\circ} \mathrm{C}$ to avoid cold sensations in the occupants [53].

In cooling mode, the heat pump is sized to provide the sensible load. The FCU lowers the air temperature below its dew point, managing in this way also the latent heat contribution, however a relative humidity punctual control is not possible. Therefore the cold water is supplied at low temperature (about $7^{\circ} \mathrm{C}$, with a design temperature difference of $\left.5^{\circ} \mathrm{C}\right)$. In this case the treated air flow was set to avoid an outlet temperature lower than $18^{\circ} \mathrm{C}$.

Table 4 and 5 summarize the heating/cooling systems main specifications. For the heating case, the parameters are the same for all the buildings in a given climatic zone. In the cooling case, instead, the buildings envelope features affect a bit the cooling system sizing. As already mentioned, in the plant with FCU a water tank is present and the 
effect of different TES volumes was also considered in the analysis in Section 5.4 [14]. A stratified sensible tank (20 temperature levels) was used (Type $4 \mathrm{a}$ ) in the model and a temperature difference of $10^{\circ} \mathrm{C}$ for the heating case and of $5^{\circ} \mathrm{C}$ for the cooling case was assumed between the inlet and outlet water of the tank at design conditions.

Table 4. Main specifications of the modelled heating systems: heat pump rated conditions, type of emission system and energy storage.

\begin{tabular}{l|ll|ll}
\hline Heating system & \multicolumn{3}{|c|}{ Underfloor } & \multicolumn{2}{c}{ FCU } \\
\hline Climatic Zone & B & E & B & E \\
\hline Heat pump rated capacity $\left[\mathrm{kW}_{\mathrm{t}}\right]$ & 2.20 & 2.80 & 3.10 & 4.20 \\
Heat pump rated condition & A7W45 & A7W45 & A7W55 & A7W55 \\
Heat pump rated COP & 3.48 & 2.00 & 2.5 & 1.55 \\
Water flow rate [kg/s] & 0.09 & 0.21 & 0.07 & 0.1 \\
Tank capacity [liters] & - & - & 40 & 60 \\
\hline
\end{tabular}

Table 5. Main specifications of the modelled cooling systems: heat pump and dehumidifier rated conditions, type of emission system and energy storage.

\begin{tabular}{|c|c|c|c|c|c|c|c|c|}
\hline \multirow{3}{*}{$\begin{array}{l}\text { Cooling system } \\
\text { Climatic Zone } \\
\text { Models }\end{array}$} & \multicolumn{4}{|c|}{ Chilled ceiling } & \multicolumn{4}{|l|}{ FCU } \\
\hline & \multicolumn{2}{|l|}{$\mathbf{B}$} & \multicolumn{2}{|l|}{$\mathbf{E}$} & \multicolumn{2}{|l|}{$\mathbf{B}$} & \multicolumn{2}{|l|}{$\mathbf{E}$} \\
\hline & $\mathbf{L}$ & $\mathbf{H}$ & $\mathbf{L}$ & $\mathbf{H}$ & $\mathbf{L}$ & $\mathbf{H}$ & $\mathbf{L}$ & $\mathbf{H}$ \\
\hline $\begin{array}{l}\text { Heat pump rated capacity } \\
{\left[\mathrm{kW}_{\mathrm{t}}\right]}\end{array}$ & 5.3 & 5.1 & 4.5 & 4.6 & 4.9 & 4.7 & 4.3 & 4.5 \\
\hline Heat pump rated conditions & A30W18 & A30W18 & A30W18 & A30W18 & A30W7 & A30W7 & A30W7 & A30W7 \\
\hline Heat pump rated $\mathrm{COP}$ & 2.88 & 2.88 & 2.88 & 2.88 & 2.15 & 2.15 & 2.15 & 2.15 \\
\hline Water flow rate $[\mathrm{kg} / \mathrm{s}]$ & 0.24 & 0.23 & 0.22 & 0.205 & 0.24 & 0.23 & 0.22 & 0.205 \\
\hline Dehumidifier rated conditions & A32RH55 & A32RH55 & A32RH55 & A32RH55 & - & - & - & - \\
\hline Dehumidifier capacity $\left[\mathrm{kW}_{\mathrm{t}}\right]$ & 3.17 & 3.17 & 3.17 & 3.17 & - & - & - & - \\
\hline $\begin{array}{l}\text { Dehumidifier rated electric } \\
\text { power }\left[\mathrm{kW}_{\mathrm{e}}\right]\end{array}$ & 1.05 & 1.05 & 1.05 & 1.05 & - & - & - & - \\
\hline
\end{tabular}

\section{RESULTS AND DISCUSSION}

As already mentioned, in order to test the energy flexibility labelling method and to identify which are the main parameters having an influence on the buildings energy flexibility, the procedure explained in Section 3 was applied to the buildings described in Section 4. According to the boundary conditions specifications described in Section 2.1, the representative winter day for Messina is February 6 and for Turin January 11, while the representative summer day for Messina is July 2 and for Turin July 8. The flexibility class is assigned by comparing the FPI with the FPI $\mathrm{I}_{\text {lim, }}$ as described in Section 3.1. In Table 6 the FPI ${ }_{\text {limit }}$ values for the considered cases are reported.

Table 6. Values of the FPIlimit for the evaluation of the flexibility class.

\begin{tabular}{c|c|c|c|c|c|c|c|c}
\hline & \multicolumn{4}{|c|}{ ME } & \multicolumn{4}{c}{ TO } \\
\hline \multirow{3}{*}{} & \multicolumn{4}{|c|}{ Heating Operation } & \multicolumn{2}{|c|}{ Cooling Operation } & Heating Operation & \multicolumn{2}{c}{ Cooling Operation } \\
\cline { 2 - 9 } & $F C U$ & Underfloor & $F C U$ & Ceiling & $F C U$ & Underfloor & $F C U$ & Ceiling \\
\cline { 2 - 9 } & 6.36 & 6.14 & 6.39 & 5.62 & 6.29 & 6.03 & 6.39 & 5.66 \\
\hline
\end{tabular}


Figure 7 shows the buildings FPI calculated for all the heating and cooling cases. In the following sections the results are discussed in detail, highlighting the influence of weather (Section 5.1), building specifications (Section 5.2), HVAC system (Section 5.3) and presence of a thermal storage (Section 5.4). In the last section (5.5), through a sensitivity analysis, the boundary conditions which most affect the results are analysed.

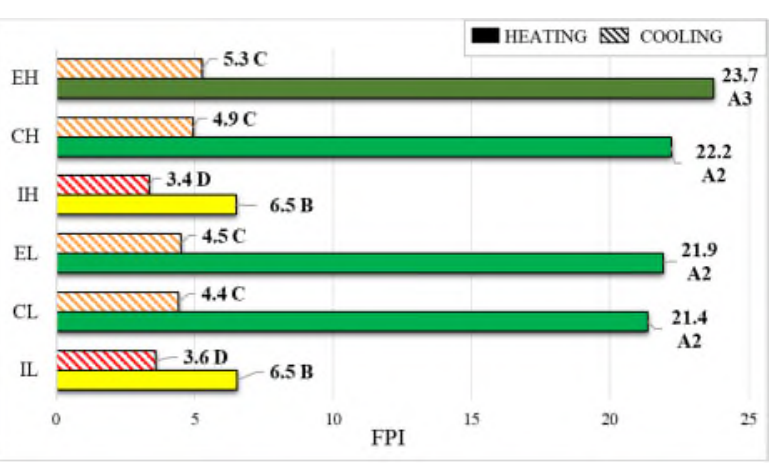

(a)

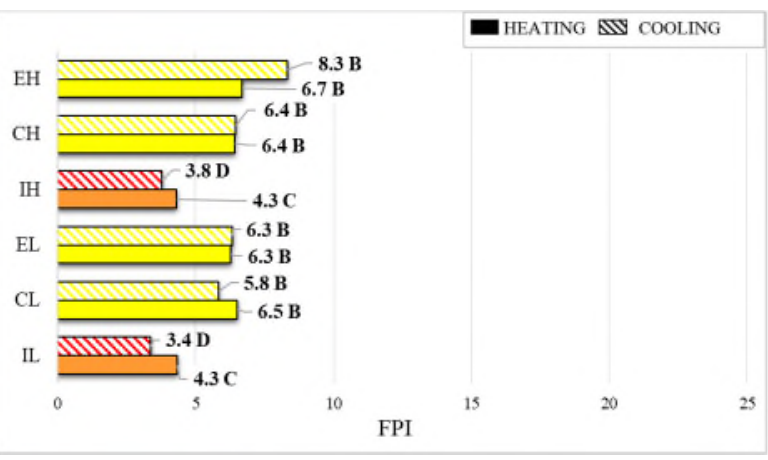

(c)

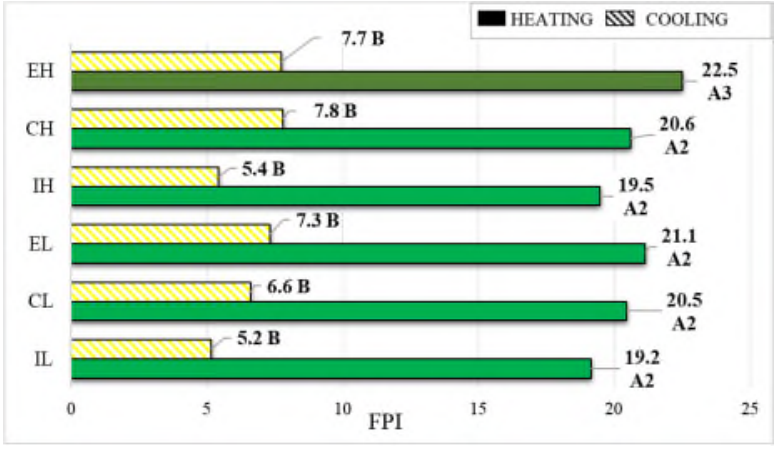

(b)

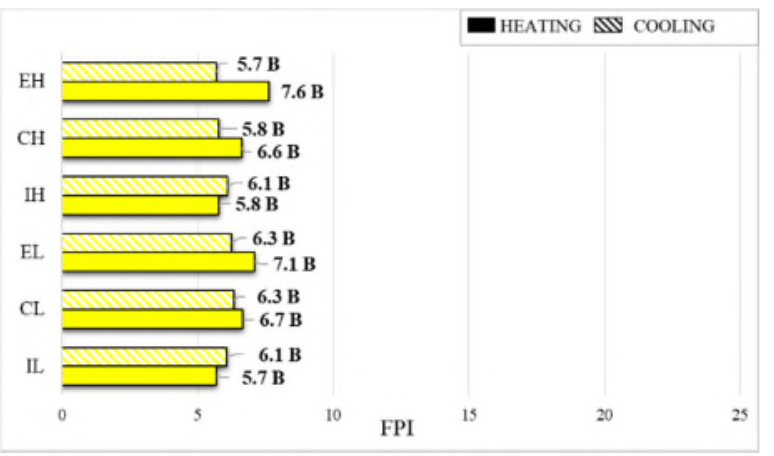

(d)

Figure 7. Buildings flexibility label for the considered case studies. (a) FPI for buildings in Messina with FCU as distribution system. (b). FPI for buildings in Messina with radiant distribution system. (c) FPI for buildings in Turin with FCU as distribution system. (d) FPI for buildings in Turin with radiant distribution system.

\subsection{Weather data influence}

It is evident from the results shown in Figure 7 that the weather data have a huge impact on the achievable flexibility performance. Indeed, comparing corresponding cases in terms of building and HVAC technical specification (i.e. Figure 7a vs Figure 7c and Figure 7b vs Figure 7d), a big difference in the FPI values, especially in the heating season, is highlighted between buildings in Southern Italy (Messina) and in Northern Italy (Turin). This means that, even if a building satisfies the energy efficiency minimum requirements (for the $U$ values reported in Table 3 these buildings belong to EPC class B), it does not necessarily provide a good level of energy flexibility. Given that the FPI is calculated in operating conditions during a limited period of time, the influence of weather data is more relevant than for the average annual energy demand used in energy performance labelling. Nevertheless the flexibility label is assigned by comparison with different reference thresholds (see Table 6), the difference between colder and warmer locations remains, putting into evidence that the weather influence cannot be completely mitigated.

In order to analyse this aspect more in depth, the behaviour of a specific building (CL) is considered in winter (equipped with a radiant floor) and summer (equipped with FCU) for the two climatic zones B and E. In Figure 8 the indoor temperature trends during the DR event in winter are shown. The indoor temperature goes down faster in Turin, even if the envelope thermal transmittance is lower (see Table 3), because the outdoor temperature is much colder 
than in Messina, where it is always above zero. Looking at Table 7, it is possible to see that the difference between the FPI values is ascribable mainly to the length of the response period, $t_{r e s}$. The building located in Messina can maintain its internal temperature within the comfort band for a time about four times greater than that of the building located in Turin. This is due to the big influence of the external temperature in the first part of the DR event (response period), when the heat pump is off. This aspect is captured by the FPI, which indeed places the buildings in two distinct flexibility classes: class A2 for the heating behaviour of the building located in Messina and class B for the building in Turin.

For the summer case similar considerations can be made. The warmer weather in Messina negatively affects the flexibility performance of the buildings in contrast with the milder summer in Turin. In Figure 9 a great influence of the external temperature during the response period can be observed and the calculated FPI represents this aspect by means of the different values of the response period duration (Table 7).

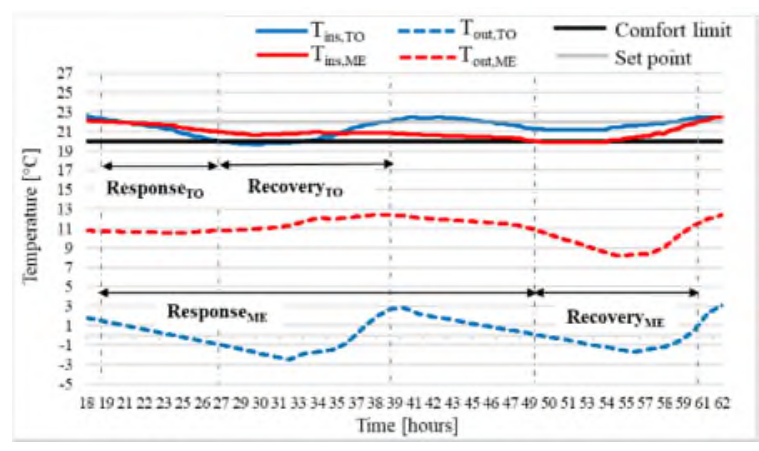

Figure 8. Outside $\left(\mathrm{T}_{\text {out }}\right)$ and inside $\left(\mathrm{T}_{\text {ins }}\right)$ temperature for a building with cavity wall insulation and light envelope (CL) equipped with underfloor heating system in Turin (TO) and Messina (ME).

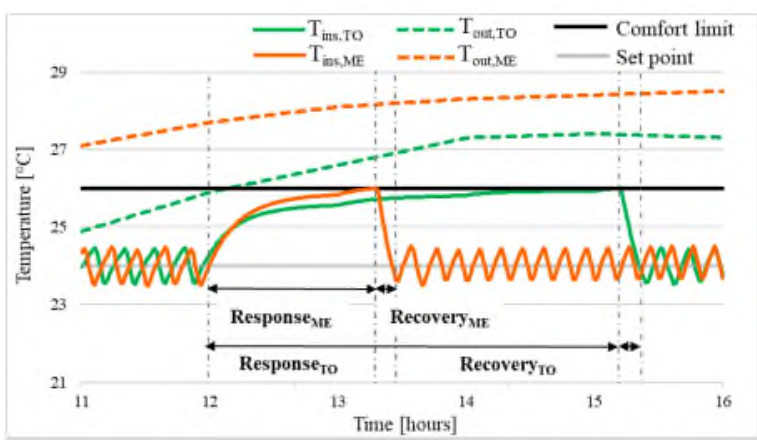

Figure 9. Outside $\left(\mathrm{T}_{\text {out }}\right)$ and inside $\left(\mathrm{T}_{\text {ins }}\right)$ temperature for a building with cavity wall insulation and light envelope (CL) equipped with FCU as cooling distribution system in Turin (TO) and Messina (ME).

Table 7. Flexibility parameters and labelling for buildings with cavity wall internal insulation and light envelope (CL).

\begin{tabular}{c|c|cccc|ccccc|cc}
\hline \multicolumn{2}{l|}{} & $\begin{array}{c}\boldsymbol{t}_{\text {res }} \\
{[\mathbf{h}]}\end{array}$ & $\begin{array}{c}\dot{\boldsymbol{P}}_{\text {res }} \\
{[\mathbf{k W}]}\end{array}$ & $\begin{array}{c}\boldsymbol{t}_{\text {rec }} \\
{[\mathbf{h}]}\end{array}$ & $\begin{array}{c}\boldsymbol{E}_{\boldsymbol{D R}} \\
{[\mathbf{k W h}]}\end{array}$ & $\mathbf{t}_{\text {res }}$ & $\dot{\boldsymbol{P}}_{\text {res }}^{*}$ & $\mathbf{t}_{\text {rec }}$ & $\boldsymbol{\eta}_{\boldsymbol{D R}}$ & $\mathbf{F P I}$ & $\begin{array}{c}\text { Flexibility } \\
\text { class }\end{array}$ \\
\hline $\begin{array}{c}\text { Underfloor } \\
\text { Heating }\end{array}$ & $M E$ & 30.03 & 0.24 & 11.28 & 6.25 & 1.25 & 0.35 & 0.47 & 0.45 & $\mathbf{2 0 . 5}$ & $\mathbf{A 2}$ \\
\hline FCU & $T O$ & 8.10 & 0.71 & 11.92 & 2.76 & 0.34 & 0.49 & 0.50 & 0.16 & $\mathbf{6 . 7}$ & $\mathbf{B}$ \\
Cooling & $T E$ & 1.30 & 0.90 & 0.13 & 0.88 & 0.05 & 0.36 & 0.01 & 0.73 & $\mathbf{4 . 4}$ & $\mathbf{C}$ & $\mathbf{B}$ \\
\hline
\end{tabular}

\subsection{Building stratigraphy influence}

In this section the influence of the building thermal mass on FPI calculation is evaluated through the variation of the insulant position and walls heaviness.

Starting from the heating case, Table 8 reports the dimensional and the dimensionless flexibility parameters for buildings located in Turin with FCU as distribution system. This case was considered because it does not include the influence of the thermal inertia of the distribution system and the location has the more severe weather conditions in winter. In general it can be observed that when the building thermal mass increases, the FPI value increases too. Considering buildings with the same walls heaviness, indeed, the external insulation and the cavity walls insulation allow a better flexibility performance than the internal insulation, because more mass can be thermally activated (i.e. the internal envelope mass delimited by the insulation layer). This is mainly represented by the parameter ( $\left.t_{\text {res }}\right)$, as shown also in Figure 10. The response period in buildings with external walls insulation is more than two times greater than that with internal insulation both for heavy and light walls (Table 8). As a consequence the actual energy variation 
is lower in case of internal insulation, even if the efficiency, $\eta_{\mathrm{DR}}$, maintains always similar values in all cases. It is evident that the insulation position and the available active thermal mass have a positive influence on the flexibility and the FPI can well represent this behaviour. For the analysed cases, moving the thermal insulation position from the inside to the outside of the wall, allows in Turin (Figure 7c) a flexibility class increase from C to B, whereas in Messina (Figure 7a) the flexibility class varies from B to A3.

On the contrary, the heaviness of the walls does not seem to have the same impact on the FPI. Even if the FPI in cases of heavy masonry increases, such increase is not relevant and the flexibility class remains the same for the same walls stratigraphy. This is confirmed by the small difference between the flexibility parameters, especially $t_{\text {res }}$, as shown in Figure 11. Eventually the variation of the overall thermal transmittance values according to the new regulations [43] does not increase consistently the FPI value (e.g. in Turin for the case CH with FCU, FPI increases from 6.4 to 7.5 , but the flexibility class remains the same, B).

Table 8. Flexibility parameters and labelling in heating case for different buildings with FCU as distribution system located in Turin.

\begin{tabular}{c|cccc|cccc|cc}
\hline & $\begin{array}{c}\boldsymbol{t}_{\text {res }} \\
{[\mathbf{h}]}\end{array}$ & $\begin{array}{c}\dot{\boldsymbol{P}}_{\text {res }} \\
{[\mathbf{k W}]}\end{array}$ & $\begin{array}{c}\boldsymbol{t}_{\text {rec }} \\
{[\mathbf{h}]}\end{array}$ & $\begin{array}{c}\boldsymbol{E}_{\boldsymbol{D R}} \\
{[\mathbf{k W h}]}\end{array}$ & $\mathbf{t} *_{\text {res }}$ & $\dot{\boldsymbol{P}}_{\text {res }}^{*}$ & $\mathbf{t}_{\text {rec }}$ & $\boldsymbol{\eta}_{\boldsymbol{D R}}$ & $\mathbf{F P I}$ & $\begin{array}{c}\text { Flexibility } \\
\text { class }\end{array}$ \\
\hline$E H$ & 5.33 & 0.573 & 0.18 & 2.91 & 0.22 & 0.18 & 0.01 & 0.99 & $\mathbf{6 . 7}$ & $\mathbf{B}$ \\
$E L$ & 5.07 & 0.556 & 0.23 & 2.82 & 0.21 & 0.19 & 0.01 & 0.87 & $\mathbf{6 . 3}$ & $\mathbf{B}$ \\
\hline$I H$ & 2.05 & 0.527 & 0.22 & 1.15 & 0.09 & 0.18 & 0.01 & 0.86 & $\mathbf{4 . 3}$ & $\mathbf{C}$ \\
$I L$ & 1.68 & 0.542 & 0.18 & 0.88 & 0.07 & 0.18 & 0.01 & 0.96 & $\mathbf{4 . 3}$ & $\mathbf{C}$ \\
\hline$C H$ & 5.10 & 0.549 & 0.22 & 2.98 & 0.21 & 0.19 & 0.01 & 0.93 & $\mathbf{6 . 4}$ & $\mathbf{B}$ \\
$C L$ & 5.02 & 0.572 & 0.20 & 2.86 & 0.21 & 0.19 & 0.01 & 0.99 & $\mathbf{6 . 5}$ & $\mathbf{B}$ \\
\hline
\end{tabular}

Looking at Figure $7 \mathrm{~b}$ and $7 \mathrm{~d}$ it is possible to extend the same conclusions above mentioned also to buildings with underfloor heating distribution system.

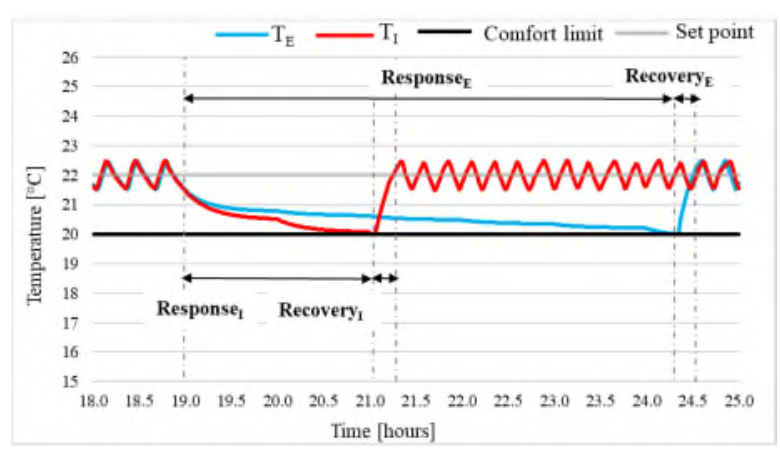

Figure 10. Comparison between inside temperature in presence of external (E) and internal (I) insulation in heating mode for a building with heavy walls and FCU distribution system in Turin.

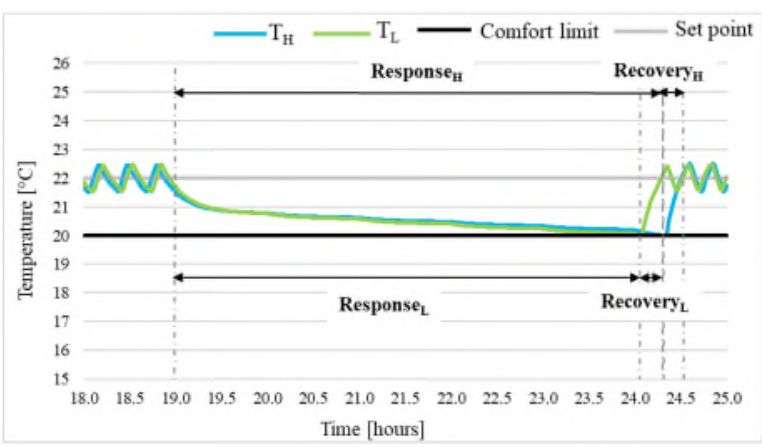

Figure 11. Comparison between inside temperature in case of heavy $(\mathrm{H})$ and light $(\mathrm{L})$ walls materials in heating mode for a building with external insulation and FCU distribution system in Turin.

Even in cooling case, in presence of FCU, moving the insulation towards the external side of the wall increases the FPI value, as for heating case (see Figures $7 \mathrm{a}$ and $7 \mathrm{c}$ ). However, for the same building, the flexibility performance is generally lower than in heating case, especially in Messina where the summer is rather hot, while winter is mild (as discussed in Section 5.1). Instead, when the chilled ceiling is used, the relationship between the thermal mass and the FPI value is less trivial and it is mainly linked to the possibility of controlling also the internal humidity. As previously explained, the chilled ceiling is coupled with a dehumidifier and the boundary comfort condition that stops the DR 
event could be both the temperature or the humidity. From the simulations results a strong connection between internal temperature and humidity trends and building envelope thermal inertia emerges. When the building thermal mass increases, the internal temperature tends to rise more slowly. The increase in internal temperature, however, counteracts the rise in relative humidity. Therefore, when the internal temperature decreases at a low rate, the relative humidity increases fast. This aspect affects the limit condition that is reached first: as shown in Figure 12, in Turin where buildings have a better level of thermal insulation, the relative humidity reaches the comfort limit condition first than the temperature for heavy and externally insulated walls. As far as FPI is concerned, typically all the analysed buildings are classified in flexibility class B. It would not be the same neglecting the comfort constraint on the relative humidity: as shown in Figure 12 the temperature takes much more time to reach its higher bound, but this aspect would detriment the indoor comfort and the evaluation would not be fair.

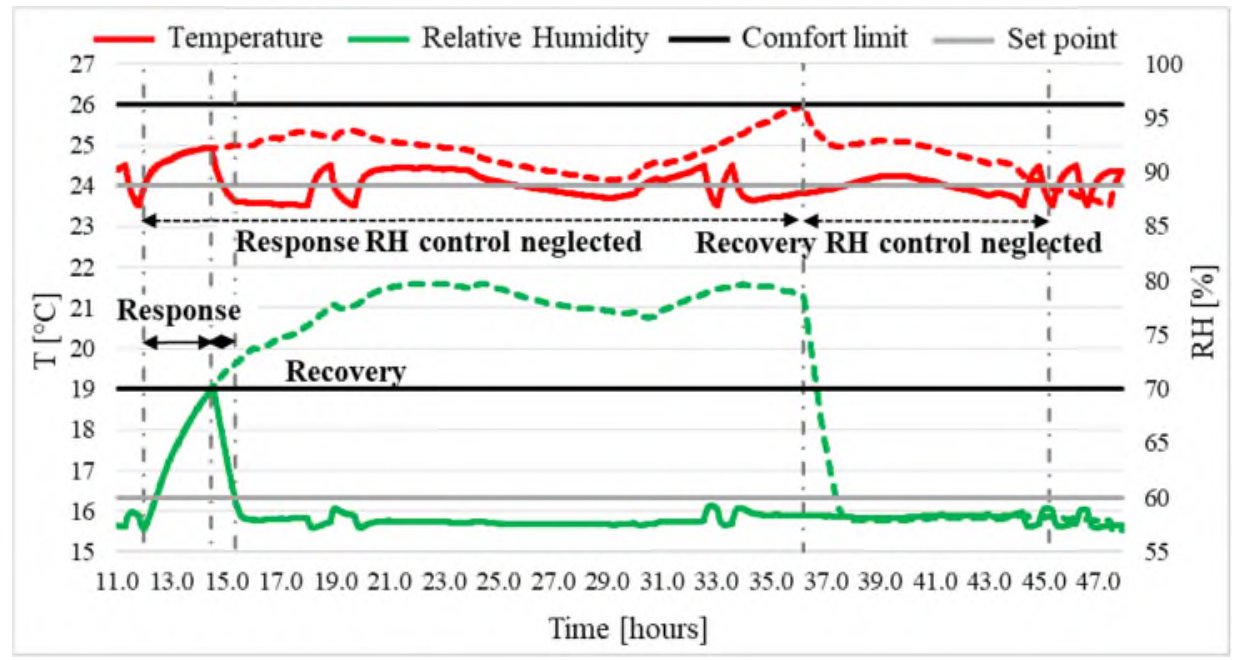

Figure 12. Temperature and relative humidity $(\mathrm{RH})$ during DR cooling case for a building located in Turin with heavy walls materials and external insulation (EH). Chilled ceiling distribution system. Continuous line: comfort constraint on both relative humidity and temperature. Dashed line: comfort constraint only on temperature.

\subsection{HVAC influence}

Figure 7 shows clearly that the influence of the thermal inertia of the distribution systems plays an important role when the building activated thermal mass is low (i.e. in case of internal insulation). To evaluate the impact of the thermal inertia introduced by the distribution system on buildings energy flexibility, a comparison between buildings with different HVAC systems but with the same internal insulation (IL) was made, trying in this way to exclude the walls thermal mass contribution from the evaluation. Table 9 reports all the flexibility parameters (dimensional and dimensionless) and FPI of such buildings.

As regards the heating case, for both locations, a great difference in the $t_{\text {res }}$ parameter between the underfloor and the FCU distribution system can be observed. The higher thermal inertia introduced by the underfloor system maintains the internal temperature within the comfort zone for a time almost five times greater than that with the FCU. However, such greater inertia affects also the recovery phase. With an underfloor heating system, the initial comfort condition restoration takes more time than for the case with FCU, which instead is very rapid. For Turin FCU takes 0.18 hours to increase the internal temperature by two degrees, while the underfloor heating almost 12 hours. The same difference can be seen in Messina. 
As far as the energy aspect is concerned, the power during the response phase, $\dot{\mathrm{P}}_{\text {res}}$, presents similar values with both distribution systems, however, looking at its dimensionless version $\left(\mathrm{P}^{*}\right.$ res, normalized with the rated power), it is possible to observe that it is bigger for radiant system because they have a lower rated installed power. Considering the last indicator, $E_{\mathrm{DR}}$ and its dimensionless version $\eta_{\mathrm{DR}}$, a great difference in the two distribution systems can be highlighted. If the underfloor heating system allows the achievement of higher actual energy savings (2.7 times greater in Turin and 3.7 in Messina compared to FCU), energy savings rates ( $\left.\eta_{\mathrm{DR}}\right)$ have an opposite trend. This is due to the great energy use during the recovery phase, which makes the total saving small compared to the energy use in reference conditions (i.e. without DR).

Table 9. Flexibility parameters and labelling for buildings with internal insulation with light walls materials (IL).

\begin{tabular}{|c|c|c|c|c|c|c|c|c|c|c|c|}
\hline & & $\begin{array}{c}t_{r e s} \\
{[\mathrm{~h}]}\end{array}$ & $\begin{array}{c}\dot{\boldsymbol{P}}_{\text {res }} \\
{\left[\mathrm{kW} \mathbf{W}_{\mathrm{e}}\right]}\end{array}$ & $\begin{array}{c}\boldsymbol{t}_{r e c} \\
{[\mathrm{~h}]}\end{array}$ & $\begin{array}{c}E_{D R} \\
{[\mathbf{k W h}]}\end{array}$ & $t^{*}$ res & $\dot{P}_{\text {res }}^{*}$ & $\mathbf{t}^{*}$ rec & $\eta_{D R}$ & FPI & $\begin{array}{c}\text { Flexibility } \\
\text { class }\end{array}$ \\
\hline TO & Underfloor & 7.22 & 0.542 & 11.73 & 2.41 & 0.30 & 0.41 & 0.49 & 0.14 & 5.7 & B \\
\hline Heating & $F C U$ & 1.68 & 0.596 & 0.18 & 0.88 & 0.07 & 0.18 & 0.01 & 0.96 & 4.3 & C \\
\hline \multirow{2}{*}{$\begin{array}{c}\text { TO } \\
\text { Cooling }\end{array}$} & $\begin{array}{c}\text { Ceiling and } \\
\text { Deum }\end{array}$ & 3.43 & 1.785 & 2.97 & 4.23 & 0.14 & 0.66 & 0.12 & 0.38 & 6.1 & B \\
\hline & $F C U$ & 0.67 & 0.746 & 0.13 & 0.35 & 0.03 & 0.33 & 0.01 & 0.53 & 3.4 & D \\
\hline $\mathrm{ME}$ & Underfloor & 28.52 & 0.230 & 12.52 & 5.23 & 1.19 & 0.34 & 0.52 & 0.38 & 19.2 & A2 \\
\hline Heating & $F C U$ & 5.78 & 0.266 & 0.40 & 1.40 & 0.24 & 0.18 & 0.02 & 0.83 & 6.5 & B \\
\hline \multirow{2}{*}{$\begin{array}{c}\text { ME } \\
\text { Cooling }\end{array}$} & $\begin{array}{c}\text { Ceiling and } \\
\text { Deum }\end{array}$ & 2.15 & 1.972 & 2.93 & 3.27 & 0.09 & 0.67 & 0.12 & 0.31 & 5.2 & B \\
\hline & $F C U$ & 0.40 & 1.150 & 0.12 & 0.21 & 0.02 & 0.46 & 0.01 & 0.42 & 3.6 & D \\
\hline
\end{tabular}

This energy flexible behaviour seems to be well represented by the FPI indicators. Underfloor heating system achieves a better flexibility class than FCU: B instead of C for Turin and A2 instead of B for Messina. Furthermore, focusing on the same heating distribution system, the flexibility performance of buildings improves if they are in Messina rather than in Turin, for the reasons mentioned in Section 5.1.

Regarding the cooling case, the radiant distribution system coupled with the dehumidifier achieves a better flexibility performance than FCU (see Table 9). In these cases, as already mentioned, it is possible to control also the humidity of the indoor air and $t_{r e s}$ is evaluated on the basis of the comfort limit condition, between temperature and humidity, reached earlier. $\dot{\mathrm{P}}_{\text {res }}$ and $\mathrm{E}_{\mathrm{DR}}$ account, therefore, for both the heat pump and the dehumidifier energy demand. Since the thermal inertia introduced by the chilled ceiling is lower than that of the underfloor heating system, the response period as well as the recovery one, although longer than that with FCU, are significantly reduced compared to the winter radiant system. However, the energy saving and the not-engaged-electric-power have improved values. The FPI label for buildings equipped with FCU is generally in a lower class than that of buildings with chilled ceiling. Furthermore the FPI shows typically a lower overall capacity to provide energy flexibility in cooling mode. It is also due to the fact that the considered cooling systems do not introduce a good level of thermal inertia as occurs with the radiant floor. For this reason in Section 5.4 the role of the introduction of a TES.

\subsection{Thermal energy storage influence}


In this section the possibility of using an external energy storage to increase the flexibility for the cases with lower performance is investigated. This can be an alternative intervention rather than actions on the building envelope. Given the low value of its FPI, the case of a building with internal insulation, light walls and FCU in Turin is considered for the heating season. The installation of a water tank in the heating plant is evaluated. The size of the tank was varied in order to guarantee thermal energy at the design heating load for variable periods of time (see Table 10). The control strategy of the distribution system is maintained the same as in the case without the storage tank. When the temperature difference between the inlet and outlet tank flow rates is below $2^{\circ} \mathrm{C}$, the water supply from the tank is stopped. The tank is supposed fully charged at the beginning of the DR event. Figure 13 and Table 10 represent how the building flexibility label changes if water tanks of different size are included: as the size of the storage increases, the flexibility performance of the building increases, even if gradually. This is due to the fact that the storage tank causes both an increase of the response and the recovery phase duration. With a 1400 litres hot water tank, the flexibility label of the considered building can pass from class $\mathrm{C}$ to $\mathrm{A} 1$.

Table 10. Flexibility parameters calculated for a building located in Turin with light walls composition, internal insulation (IL) and FCU distribution system with different thermal energy storage tank size (heating case).

\begin{tabular}{cc|cccc}
\hline $\begin{array}{c}\text { Storage size } \\
\text { [litres] }\end{array}$ & $\begin{array}{c}\text { Heating autonomy } \\
{[\mathbf{m i n}]}\end{array}$ & $\begin{array}{c}\boldsymbol{t}_{\text {res }} \\
{[\mathbf{h}]}\end{array}$ & $\begin{array}{c}\dot{\boldsymbol{P}}_{\text {res }} \\
{[\mathbf{k W}]}\end{array}$ & $\begin{array}{c}\boldsymbol{t}_{\text {rec }} \\
{[\mathbf{h}]}\end{array}$ & $\begin{array}{c}\boldsymbol{E}_{\boldsymbol{D R}} \\
{\left[\mathbf{k W h} \mathbf{W h}_{\mathbf{e}}\right]}\end{array}$ \\
\hline 0 & 0 & 1.68 & 0.542 & 0.18 & 0.88 \\
200 & 30 & 3.32 & 0.518 & 0.25 & 1.15 \\
400 & 70 & 5.15 & 0.520 & 0.35 & 2.40 \\
600 & 100 & 6.33 & 0.600 & 0.48 & 3.43 \\
1000 & 170 & 9.82 & 0.762 & 2.98 & 5.28 \\
1400 & 230 & 12.15 & 0.887 & 3.03 & 7.92 \\
\hline
\end{tabular}

Table 11. Flexibility parameters calculated for a building located in Messina with heavy walls composition, internal insulation (IH) and FCU distribution system with different thermal energy storage tank size (cooling case).

\begin{tabular}{cc|cccc}
\hline $\begin{array}{c}\text { Storage size } \\
{[\text { litres] }}\end{array}$ & $\begin{array}{c}\text { Cooling } \\
\text { autonomy [min] }\end{array}$ & $\begin{array}{c}\boldsymbol{t}_{\text {res }} \\
{[\mathbf{h}]}\end{array}$ & $\begin{array}{c}\dot{\boldsymbol{P}}_{\text {res }} \\
{[\mathbf{k W}]}\end{array}$ & $\begin{array}{c}\boldsymbol{t}_{\text {rec }} \\
{[\mathbf{h}]}\end{array}$ & $\boldsymbol{E}_{\boldsymbol{D R} \text { R }}[\mathbf{k W h}]$ \\
\hline 0 & 0 & 0.43 & 1.023 & 0.13 & 0.20 \\
400 & 30 & 1.23 & 0.886 & 0.20 & 0.79 \\
800 & 60 & 2.18 & 0.922 & 0.25 & 1.63 \\
1200 & 90 & 3.98 & 0.947 & 0.43 & 3.22 \\
2000 & 150 & 6.22 & 0.974 & 0.57 & 5.26 \\
3200 & 230 & 9.38 & 0.938 & 0.37 & 8.23 \\
\hline
\end{tabular}

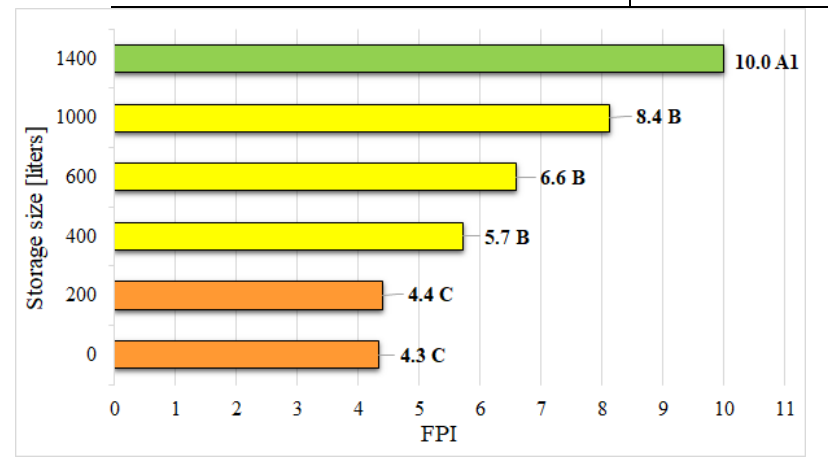

Figure 13. FPI and flexibility classes calculated for a building located in Turin with light walls composition, internal insulation (IL) and FCU distribution system with different energy storage size (heating case).

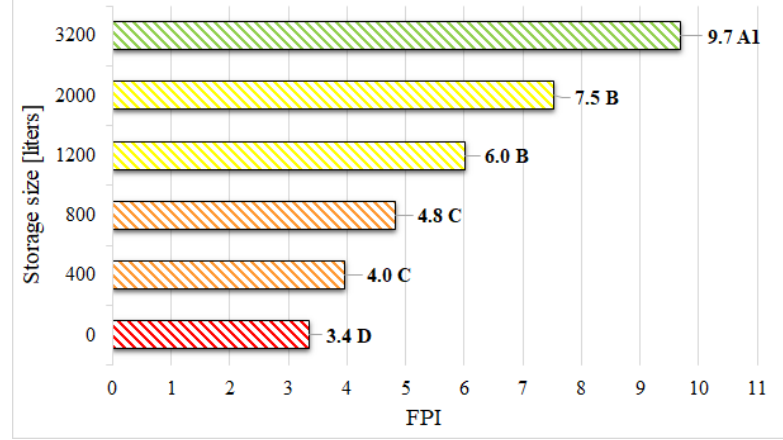

Figure 14. FPI and flexibility classes calculated for a building located in Messina with heavy walls composition, internal insulation and FCU distribution system with different energy storage size (cooling case). 
As far as cooling is concerned, the same analysis can be made. By considering the case with the worst flexibility performance (i.e. a building with heavy walls, internal insulation and FCU in Messina), the effect of the energy storage tank in the cooling plant is evaluated (Figure 14 and Table 11). The FPI increase with the TES size is slower than in heating case. This fact highlights once again that the thermal inertia, whether it is supplied by the cooling system or by the building envelope, has less impact in cooling case.

Looking at the results in Table 11, it is evident that the tank size increases the response time, because more energy can be stored and supplied to the building during the DR event when the HP is off. On the other side, it affects less the recovery period, because the system is able to supply cooling to the building also during recharging.

\subsection{Sensitivity analysis}

In this section a sensitive analysis is performed in order to evaluate the influence of the boundary conditions selected in Section 2.1 on the calculation of the FPI. In detail the choice of the DR event and its starting time and the choice of the representative day are considered.

\subsubsection{DR event}

A valley filling strategy (VFS) is considered as alternative DR event, instead of a peak shaving strategy. VFS is defined as an increase in power supply to the heating/cooling system when the electric system minimum power demand occurs (LLP, see Figure 1). The response period goes from the beginning of the event to the moment when the internal condition reaches its limit $\left(22^{\circ} \mathrm{C}\right.$ in heating season starting from $20^{\circ} \mathrm{C}$ and $24^{\circ} \mathrm{C}$ in cooling one, starting from $26^{\circ} \mathrm{C}$ ). The recovery period ends when the initial internal condition is restored by the heating/cooling system. In this case the flexibility parameters related to the engaged electric power $\left(\dot{\mathrm{P}}_{\mathrm{res}}\right)$ and the actual energy variation $\left(\mathrm{E}_{\mathrm{DR}}\right)$ are calculated in the same way as in the PSS case, even if they assume a different meaning. $\dot{P}_{\text {res }}$, for the way in which it is calculated, has a negative sign, since it represents the surplus electric power engaged during the response period. The $\mathrm{E}_{\mathrm{DR}}{ }^{3}$, instead represents the effective electricity overconsumption during the whole DR event. It also tends to be negative, given its formulation in Eq. 3 (in Eq.7, if the energy variation is positive, the efficiency is taken zero similarly to PSS). The winter and summer representative days are the same as for the case PSS. The starting time of the event is derived from the observation of the market daily balancing energy, available on Terna website [33]: for the Italian case, both in winter and summer, two off peak periods are identified at $4.00 \mathrm{am}$ and at $2.00 \mathrm{pm}$. So, taking for each season the most severe case, the DR event starts at $4.00 \mathrm{am}$ for heating case and at $2.00 \mathrm{pm}$ for cooling case.

The results shown in Figure 15, for heavy buildings with central insulation $(\mathrm{CH})$ and FCU, highlight that a different FPI is obtained compared with PSS, but the difference is not so big, unless for one case (heating case in Messina). In the latter the flexibility class changes and it is mainly due to the shorter duration of the response phase in case of VFS compared to PSS.

\subsubsection{Representative day}

Another boundary condition which can affect the FPI is the representative day used in the calculations. Instead of considering the average daily temperatures to choose such a day, it is evaluated the effect of taking the most extreme days in terms of temperature: the coldest for winter and the hottest for summer. Looking at Figure 15, all the FPI values decrease, both for heating and cooling case, in comparison with the standard configuration. The extreme case

\footnotetext{
${ }^{3}$ Since for the non-dimensional $E_{D R}$ calculation the denominator is represented by the electric consumption in reference conditions during $t_{D R}$, if this is zero, a unitary $\eta_{D R}$ is assumed.
} 
is in Messina in heating season, where the FPI decreases down to 8.7 from 22.2 making the flexibility class B instead of A2. Here in cooling season, instead, FPI slightly decreases and the labelling class remains C, meaning that in summer the monthly average outside temperature assumes pretty high values and close to the maximum one. Given also the influence of the daily temperature, it is considered convenient to choose a representative day whose climatic conditions are closer to an average occurrence for the location.

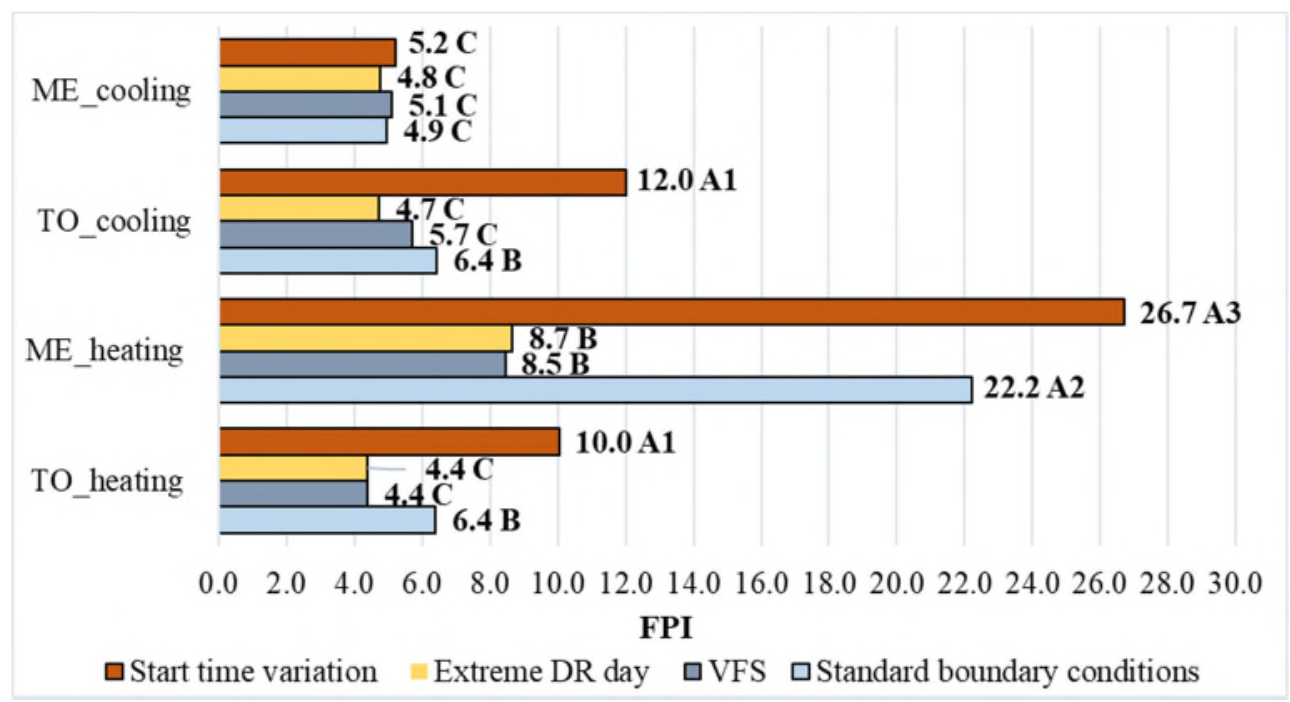

Figure 15. FPI and flexibility classes calculated for a building with heavy walls composition, cavity insulation $(\mathrm{CH})$ and FCU distribution system with different test boundary conditions: results for the boundary standard conditions are compared with a different starting time of the DR event, a different representative day and a different DR event (valley filling strategy).

\subsubsection{DR event starting time}

Finally, it is important to underline that also the DR starting time affects the results. In general, shifting the DR starting time to the other power electric peak of the daily electric energy demand curve increases the buildings flexibility performance. Calculating the FPI in winter season for the same building as in Figure 15 when the DR starting time is $11.00 \mathrm{am}$ instead of $7.00 \mathrm{pm}$, the FPI increases to 26.7 (class A3) for Messina and to 10.0 (class A1) for Turin. In cooling case, shifting the DR starting time from 12.00 to $6.00 \mathrm{pm}$, the buildings flexibility performance increases too. In Turin the flexibility label switches to A1 (FPI=12), while in Messina the flexibility class remains C but the FPI value increases (up to 5.2 from 4.9).

\section{CONCLUSIONS}

This paper proposes a methodology to label buildings with electric heating/cooling systems according to their energy flexibility in design conditions. The energy flexibility label is based on the introduction of a single indicator (the Flexibility Performance Indicator) which summarizes four flexibility parameters (response time $\mathrm{t}_{\mathrm{res}}$, committed power $\dot{\mathrm{P}}_{\text {res }}$, recovery time $t_{r e c}$, actual energy variation $\left.E_{D R}\right)$. Given the dependency of the flexibility quantification on the boundary conditions, the demand response event, representative day and comfort constraints were defined in a unique way for the application of the proposed methodology. Furthermore dynamic simulations are necessarily requested for the Flexibility Performance Indicator calculation. 
In order to prove its reliability, the methodology was tested on different Italian buildings in which the geographical position and the thermal inertia introduced by both the buildings envelope (construction materials or wall composition) and the heating/cooling generation and emission systems were changed. The aim of the analysis was also to highlight which are the aspects with a bigger influence on buildings flexibility behaviour. Some conclusions are summarized in the following:

- Results showed a great influence of external weather conditions on the flexibility performance: in cold winter periods, the flexibility performance drops as well as in hot summer periods. Even if the building presents good energy performance, the energy labelling does not correspond with the flexibility labelling, meaning that the building thermal properties that satisfy the prescription for limiting the energy demand do not guarantee always a big flexibility.

- The envelope thermal inertia has an important role for buildings flexibility performance (external insulation is recommended), especially in heating case.

- High thermal inertia emission systems (i.e. underfloor heating and ceiling cooling) are helpful in achieving good energy flexibility, in particular in presence of low building structure inertia (i.e. internal insulation). As far as cooling is concerned, the analysis led to the conclusion that increasing the building or the heating/cooling emission system thermal inertia increases the flexibility performance but not with the same entity as in heating case.

- The addition of a thermal energy storage in the heating/cooling systems in case of low energy flexibility can help in improving the achievable flexibility class. By increasing the thermal energy storage volume, the energy performance is improved. In summer a bigger volume (more than double) than in winter is necessary to reach the same flexibility level.

In general, the Flexibility Performance Indicator seems to quantify well the building energy flexibility during a demand response event. However, in some cases, it proved to be very sensitive to some boundary conditions such as the demand response event or representative day. Thus the need of establishing univocal boundary conditions when assessing the Flexibility Performance Indicator is confirmed, so to obtain values to be compared for different buildings configurations and locations.

\section{ACKNOWLEDGMENT}

This work has been supported by MIUR of Italy in the framework of PRIN2015 project: "Clean heating and cooling technologies for an energy efficient smart grid", Prot. 2015M8S2PA.

\section{NOMENCLATURE}

A

AWHP

$\mathrm{C}$

CHP

COP

DD

DEUM

DR external air conditions

air water heat pump

cavity wall

combined heat and power

coefficient of performance

degree days

dehumidifier

demand response 


\begin{tabular}{|c|c|}
\hline DSM & demand side management \\
\hline $\mathrm{E}$ & external insulation \\
\hline $\mathrm{E}_{\mathrm{DR}}$ & actual energy variation \\
\hline $\mathrm{EPC}$ & energy performance certificate \\
\hline FCU & fan coil unit \\
\hline FPI & flexibility performance indicator \\
\hline $\mathrm{FPI}_{\text {limit }}$ & limit value of flexibility performance indicator \\
\hline $\mathrm{H}$ & heavy wall \\
\hline HLP & high load period \\
\hline HP & heat pump \\
\hline HVAC & heating, ventilation and air conditioning system \\
\hline I & internal insulation \\
\hline $\mathrm{L}$ & light wall composition \\
\hline LLP & low load period \\
\hline $\mathrm{ME}$ & Messina \\
\hline nZEBs & nearly Zero Energy Buildings \\
\hline$\dot{\mathrm{P}} *_{\text {res }}$ & dimensionless committed power effect \\
\hline $\mathrm{PCM}$ & phase change material \\
\hline$\dot{\mathrm{P}}_{\mathrm{DR}}$ & electric power in DR event case \\
\hline $\mathrm{p}_{\mathrm{i}}$ & weight \\
\hline$\dot{\mathrm{P}}_{\text {rated }}$ & heat pump design power \\
\hline$\dot{\mathrm{P}}_{\mathrm{REF}}$ & electric power in reference case without DR event \\
\hline$\dot{\mathrm{P}}_{\text {res }}$ & committed power in response period \\
\hline PSS & peak shaving strategy \\
\hline $\mathrm{RBC}$ & rule-based control \\
\hline RES & renewable energy sources \\
\hline RH & relative humidity \\
\hline SRI & smart readiness indicator \\
\hline $\mathrm{T}$ & temperature \\
\hline $\mathrm{t}^{*}$ rec & dimensionless recovery time \\
\hline$t^{*}$ res & dimensionless response time \\
\hline TCL & thermostatically controlled loads \\
\hline$t_{\mathrm{DR}}$ & DR event duration \\
\hline TES & thermal energy storage \\
\hline THR & total horizontal radiation \\
\hline TMY & typical meteorological year \\
\hline TO & Torino \\
\hline $\mathrm{t}_{\mathrm{rec}}$ & recovery time \\
\hline $\mathrm{t}_{\mathrm{res}}$ & response time \\
\hline $\mathrm{U}$ & thermal transmittance \\
\hline VFS & valley filling strategy \\
\hline
\end{tabular}




\section{REFERENCES}

[1] European Parliament, "Directive 2012/27/EU of the European Parliament and of the Council of 25 October 2012 on energy efficiency, amending Directives 2009/125/EC and 2010/30/EU and repealing Directives 2004/8/EC and 2006/32/EC," Official Journal of the European Union, no. OJ L 315. pp. 1-56, 2012.

[2] European Parliament, "Directive (EU) 2018/844 of the European Parliament and of the Council of 30 May 2018 amending Directive 2010/31/EU on the energy performance of buildings and Directive 2012/27/EU on energy efficiency (Text with EEA relevance)," Official Journal of the European Union, no. L 156/75. pp. 7591, 2018.

[3] European Parliament, "Energy. Topics: Energy Efficiency. Buildings," 2018. [Online]. Available: https://ec.europa.eu/energy/en/topics/energy-efficiency/buildings. [Accessed: 17-Dec-2018].

[4] European Parliament; European Council, "Directive 2009/28/EC on the promotion of the use of energy from renewable sources," Official Journal of the European Union, no. OJ L 140. pp. 16-62, 2009.

[5] R. Zafar, A. Mahmood, S. Razzaq, W. Ali, U. Naeem, and K. Shehzad, "Prosumer based energy management and sharing in smart grid," Renewable and Sustainable Energy Reviews, vol. 82, pp. 1675-1684, 2018.

[6] European Heat Pump Assoication, "European Heat Pump Market and Statistics," 2014.

[7] International Energy Agency (IEA), “Space cooling : More access , more comfort, less energy,” no. 1, 2017.

[8] I. Colak, G. Fulli, S. Sagiroglu, M. Yesilbudak, C.F. Covrig, "Smart grid projects in Europe: Current status, maturity and future scenarios", Applied Energy, vol. 152, pag. 58-70, 2015.

[9] S. Ø. Jensen, A. M. Pomianowsk, R. Lollini, W. Pasut, A. Knotzer, P. Engelmann, A. Stafford, G. Reynders, "IEA EBC Annex 67 Energy Flexible Buildings," Energy and Buildings, vol. 155, pp. 25-34, 2017.

[10] International Energy Agency (IEA): Annex 42, Heat Pumps in Smart Grids Technology Collabortation Programme on Heat Pumping Technologies. 2017.

[11] Y. Chen, P. Xu, J. Gu, F. Schmidt, and W. Li, "Measures to improve energy demand flexibility in buildings for demand response (DR): A review," Energy and Buildings, vol. 177, pp. 125-139, 2018.

[12] G. Reynders, J. Diriken, and D. Saelens, "Generic characterization method for energy flexibility: Applied to structural thermal storage in residential buildings," Applied Energy, vol. 198, pp. 192-202, 2017.

[13] S. Stinner, K. Huchtemann, and D. Müller, "Quantifying the operational flexibility of building energy systems with thermal energy storages," Applied Energy, vol. 18, pp. 140-154, 2016.

[14] A. Arteconi, N. J. Hewitt, and F. Polonara, "Domestic demand-side management (DSM): Role of heat pumps and thermal energy storage (TES) systems," Applied Thermal Engineering, vol. 51, pp. 155-165, 2013.

[15] J. Lizana, D. Friedrich, R. Renaldi, and R. Chacartegui, "Energy flexible building through smart demand-side management and latent heat storage," Applied Energy, vol. 230, pp. 471-485, 2018.

[16] European Parliament, "DIRETTIVA 2010/31/UE DEL PARLAMENTO EUROPEO E DEL CONSIGLIO del 19 maggio 2010 sulla prestazione energetica nell'edilizia," Official Journal of the European Union, vol. L153/13. pp. 13-35, 2010.

[17] S. Verbeke, Y. Ma, P. V. Tichelen, S. Bogaert, P. Waide, M. Uslar, J. Schulte, K. Bettgenhäuser, A. John, A. Hermelink, M. Offermann, J. Groezinger, "Support for Setting up a Smart Readiness Indicator for Building and Related Impact Assessment Final Report," no. August, p. 288, 2018.

[18] S. Ø. Jensen, H. Madsen, R. Lopes, R. G. Junker, D. Aelenei, R. Li, S. Metzger, K. B. Lindberg, A. J. Marszal, M. Kummert, B. Bayles, E. Mlecnik, R. Lollini, W. Pasut, “Annex 67: Energy Flexible Buildings - Energy Flexibility as a key asset in a smart building future Contribution," no. November, pp. 1-16, 2017.

[19] G. Reynders, R. Amaral Lopes, A. Marszal-Pomianowska, D. Aelenei, J. Martins, and D. Saelens, "Energy flexible buildings: An evaluation of definitions and quantification methodologies applied to thermal storage," Energy and Buildings, vol. 166, pp. 372-390, 2018.

[20] J. Le Dréau and P. Heiselberg, "Energy flexibility of residential buildings using short term heat storage in the thermal mass," Energy, vol. 111, pp. 991-1002, 2016.

[21] R. De Coninck and L. Helsen, "Quantification of flexibility in buildings by cost curves - Methodology and application," Applied Energy, vol. 162, pp. 653-665, 2016.

[22] R. D'hulst, W. Labeeuw, B. Beusen, S. Claessens, G. Deconinck, and K. Vanthournout, "Demand response flexibility and flexibility potential of residential smart appliances: Experiences from large pilot test in Belgium," Applied Energy, vol. 155, pp. 79-90, 2015.

[23] T. Nuytten, B. Claessens, K. Paredis, J. Van Bael, and D. Six, "Flexibility of a combined heat and power system with thermal energy storage for district heating," Applied Energy, vol. 104, pp. 583-591, 2013.

[24] A. Arteconi and F. Polonara, "Assessing the demand side management potential and the energy flexibility of heat pumps in buildings," Energies, vol. 11, p. 1846, 2018-

[25] R. G. Junker, A. G.Azara, R. A. Lopes, K. B. Lindberg, G. Reynders, R. Relan, H. Madsen, “Characterizing 
the energy flexibility of buildings and districts," Applied Energy, vol. 225, pp. 175-182, 2018.

[26] K. Foteinaki, R. Li, A. Heller, and C. Rode, "Heating system energy flexibility of low-energy residential buildings," Energy and Buildings, 2018.

[27] A. Mugnini, F. Polonara, A. Arteconi, "Design energy flexibility for Italian residential buildings", 5th International High Performance Buildings Conference at Purdue, 330, pp. 1-10, 2018.

[28] A. J. Veldhuis, M. Leach, A. Yang, "The impact of increased decentralised generation on the reliability of an existing electricity network", Applied Energy, vol. 215, pag. 479-502, 2018.

[29] T. Q. Péan, J. Salom, and R. Costa-Castelló, "Review of control strategies for improving the energy flexibility provided by heat pump systems in buildings," Journal of Process Control, 2018.

[30] P. O. Fanger, Thermal comfort: analysis and applications in environmental engineering. McGraw-Hill Book Company (1970), 1970.

[31] G. Pernigotto, A. Prada, D. Cóstola, A. Gasparella, and J. L. M. Hensen, "Multi-year and reference year weather data for building energy labelling in north Italy climates," Energy and Buildings, vol. 72, pp. 62-72, 2014.

[32] N. Italiana and L. Uni, "UNI 10349-1. Heating and cooling of buildings - Climatic data - Part 1: Monthly means for evaluation of energy need for space heating and cooling and methods for splitting global solar irradiance into the direct and diffuse parts and for calculate the sol," 2016.

[33] T. S.p.a, "Daily Italian electricity demand.” [Online]. Available: http://www.terna.it/.

[34] U. N. I. (Ente italiano di unificazione), "UNI/TS 11300-1. Energy performance of buildings. Part 1: Evaluation of energy need for space heating and cooling." 2014.

[35] U. N. I. italiano di unificazione), "UNI/TR 10349-2. Heating and cooling of buildings - Climatic data - Part 2: Data for design load.," 2016.

[36] T. Trnsys and E. Programs, "Trnshell \& trnsed."

[37] TESS, “Trnsys 17- Weather Data," vol. 8, pp. 1-79, 2013.

[38] M. of I. E. Development, "Decree of 11th March 2008 for the definition of the limit values of annual primary energy requirement and thermal transmittance," Gazzetta ufficiale, 2008.

[39] European Commission DG Environment, "Green Public Procurement Wall Panels Technical Background Report," no. June, 2010.

[40] U. N. I. italiano di unificazione), "UNI/TR 11552. Abacus of the structures constituting the opaque envelope of the thermophysical buildings.," 2014.

[41] U. N. I. italiano di unificazione), "UNI 10351:1994/EC. Building materials: Thermal conductivity and vapor permeability," 1994.

[42] U. N. I. (Ente italiano di unificazione), "UNI EN 12524. Building materials and products: Hygrothermal properties," 2011.

[43] M. of I. E. Development, "Interministerial Decree of 26 June 2015 - Application of calculation methods for energy performance and definition of minimum building requirements.," Gazzetta ufficiale, 2015.

[44] "Eurostat Statistics Explained." [Online]. Available: https://ec.europa.eu/eurostat/statisticsexplained/index.php/Housing_statistics/it. [Accessed: 18-Dec-2018].

[45] M. of I. E. Development, "Italian Ministerial Decree of 5th July 1975: Modification to the ministerial instructions dated 20th June 1896 concerning the minimal height and the main hygienic-sanitary requirements in housing units," vol. 1975, pp. 18-20, 1975.

[46] U. N. I. (Ente italiano di unificazione), "UNI EN ISO 7730:2006. Ergonomics of the thermal environment Analytical determination and interpretation of thermal comfort using calculation of the PMV and PPD indices and local thermal comfort criteria. ICS 13.180." 2006.

[47] D. Fischer and H. Madani, "On heat pumps in smart grids: A review," Renewable and Sustainable Energy Reviews. 2017.

[48] Viessmann, "VITOCAL 200-S, Air to water heat pump with DC inverter technology for heating and cooling." 2016.

[49] C. Pizzetti, Condizionamento dell'aria e refrigerazione. Teoria e calcolo degli impianti. 1986.

[50] R. and A.-C. E. (ASHRAE) American Society of Heating, ASHRAE HANDBOOK FUNDAMENTALS. 1791 Tullie Circle, N.E., Atlanta, GA 30329, 2005.

[51] M. Doninelli, "Gli impianti a pannelli radianti (radiant panel systems).," Idrauilica Caleffi, vol. 9, 1991.

[52] Solar Energy Laboratory, "Trnsys 17 Multizone Building modeling with Type56 and TRNBuild," University Wisconsin-Madison, vol. 5, pp. 1-29, 2012.

[53] M. Doninelli, "I circuiti e i terminali degli impianti di climatizzazione (the circuits and the terminals of the air conditioning systems)." 